(C) Dereito Vol.27, n01:119-152 (Xaneiro-Xuño, 2018) • ISSN 1132-9947

\title{
LA EVOLUCIÓN DEL CONCEPTO DE CONSUMIDOR EN EL ORDENAMIENTO INTERNO Y EN LA UNIÓN EUROPEA
}

The evolution of the consumer concept in the European Union and in the Spanish context

DOI: http://dx.doi.org/10.15304/dereito.27.1.4108.5576

María Jesús Sande Mayo

Doctora en Derecho

Centro de Estudios Garrigues

Mariajesus.sandemayo@gmail.com

\section{Resumen}

La delimitación del concepto de consumidor ha planteado históricamente dificultades, no sólo porque se trata de concepto que admite varias acepciones -que también-, sino porque con frecuencia resulta difícil determinar cuándo un sujeto actúa en el marco de una actividad, oficio o profesión o, por el contrario, lo hace con fines privados. Tanto en el plano de la Unión Europea como a nivel interno, el concepto de consumidor ha ido flexibilizándose, y en el estudio de tal tendencia nos centraremos en estas líneas. Igualmente, nos detendremos en las diferencias que existen en el contexto de la Unión Europea y en el ámbito del Derecho Español en lo que a dicho concepto se refiere, pues si bien en el primero sólo obtienen tal consideración las personas físicas, en el segundo, bajo ciertas circunstancias, también podrán obtener el amparo de la normativa tuitiva de los consumidores las personas jurídicas y los entes sin personalidad.

Palabras clave: Consumidor, persona jurídica, ente sin personalidad, Derecho de la Unión Europea, TRLGDCU.

\section{Abstract}

The delimitation of the concept of consumer has historically raised difficulties, not only because it is a term that presents various meanings, but also because it is often difficult to determine when a subject acts outside of an activity, trade or profession and when does it for purposes exclusively private. Both at the level of the European Union and in the Spanish context, the concept of consumer has become more flexible, and we will study that evolution in this lines. Besides, we will focus on the differences that exist within the framework of the European Union and in the context of Spanish Law as far as this concept is concerned.

Keywords: Consumer, legal person, entity without personality, European Union Law, TRLGDCU.

\section{SUMARIO}

1. INTRODUCCIÓN.- 2. LA NOCIÓN DE CONSUMIDOR EN EL DERECHO DE LA UNIÓN EUROPEA.- 2.1. EN EL DERECHO PRIMARIO. 2.2. EN EL DERECHO CONVENCIONAL.- 2.3. EN EL DERECHO DERIVADO.- 2.4. EL

Recibido: 07/06/2017. Aceptado: 18/07/2017. 
CONSUMIDOR MEDIO Y VULNERABLE.- 3. LA NOCIÓN DE CONSUMIDOR EN LA NORMATIVA ESPAÑOLA.- 3.1. EN LA LGDCU Y EN EL TRLGDCU.3.2. EN EL TRLGDCU TRAS LA LEY 3/2014.- 3.2.1. EL CONSUMIDOR PERSONA FÍSICA.- 3.2.2. LOS CONSUMIDORES PERSONA JURÍDICA Y ENTE SIN PERSONALIDAD.- 4. BIBLIOGRAFÍA.

\section{SUMMARY}

1. INTRODUCTION.- 2. THE NOTION OF CONSUMER IN THE LAW OF THE EUROPEAN UNION.- 2.1. IN PRIMARY LAW. 2.2. IN CONVENTIONAL LAW.2.3. IN DERIVATIVE LAW.- 2.4. THE AVERAGE AND VULNERABLE CONSUMER.- 3. THE NOTION OF CONSUMER IN THE SPANISH REGULATIONS.- 3.1. IN THE LGDCU AND IN THE TRLGDCU.- 3.2. IN THE TRLGDCU AFTER THE LAW 3 / 2014.- 3.2.1. THE INDIVIDUAL CONSUMER.- 3.2.2. CONSUMERS LEGAL ENTITY AND ENTITY WITHOUT PERSONALITY.- 4. BIBLIOGRAPHY.

\section{INTRODUCCIÓN}

La expresión «consumidor» se encuentra a día de hoy plenamente asentada en el lenguaje jurídico ${ }^{1}$, aunque su origen se adscribe a la ciencia económica ${ }^{2}$, en la que es concebido como un sujeto de mercado que adquiere bienes o utiliza servicios para la satisfacción de sus necesidades personales o familiares, siendo su pretensión hacerse con el «valor de uso» de lo adquirido y no con su «valor de cambio» ${ }^{3}$. Este último, sería el objetivo propio del empresario, el cual actúa con la finalidad no ya de recuperar su inversión, sino de multiplicarla ${ }^{4}$.

En lo relativo al sentido jurídico del término, no resulta posible comprender su origen sin vincularlo al movimiento de protección de los consumidores $^{5}$. De ahí que debamos acercarnos en un primer orden de cosas a la evolución experimentada en este ámbito.

El germen del movimiento de defensa de los consumidores se encuentra en Estados Unidos, representando la experiencia norteamericana «el capítulo más completo e interesante de la historia de la tutela del consumidor» ${ }^{6}$. Fue en este país donde nacieron las primeras

\footnotetext{
1 El Diccionario de la Real Academia Española, en su $22^{a}$ ed., asigna a la voz «consumidor» dos acepciones: «Que consume» y «Persona que compra productos de consumo».

${ }^{2}$ Así lo señala N. ReICH, Mercado y Derecho (trad. de FoNT), Ariel, Barcelona, 1985, p. 170.

3 Vid. J. E. CASTAÑEdA MuÑOz, «Nota breve sobre el concepto de consumidor», en Cuadernos de Estudios Empresariales, vol. 12, 2002, p. 316.

${ }^{4}$ Vid. G. A. Botana García, «La noción de consumidor», en Botana García, G. A., Ruiz MuÑoz, M. (Coords.), Curso sobre protección jurídica de los consumidores, McGraw-Hill, Madrid, 1999, p. 28.

${ }^{5}$ Vid. en este sentido A. ACEDO PENCO, «La noción de consumidor y su tratamiento en el Derecho Comunitario, Estatal y Autonómico. Breve referencia al concepto de consumidor en el Derecho extremeño», en Anuario de la Facultad de Derecho, núm. 18, 2000, pp. 299 y ss.

${ }^{6}$ Vid. De León ArCe, en A. De León ArCe; L. M. García García, (Coords.), Derechos de los consumidores y usuarios, vol. 1, Tirant lo Blanch, Valencia, 2007, pp. 49 a 50.
} 
organizaciones de consumidores, situándose como primer precedente la «Liga de Consumidores», creada en $1891^{7}$. Como hitos destacables de este fenómeno cabe destacarla publicación en 1927 del libro «Your Money's Worth», que contribuyó de forma decisiva a concienciar a la población americana acerca de la necesidad de proteger a los consumidores ${ }^{8}$, influyendo a la postre en la constitución, sólo nueve años más tarde, de la primera asociación de consumidores de carácter estatal, la Consumer's Union of Unite States ${ }^{9}$.

Por su parte, las primeras leyes en defensa del consumidor fueron promulgadas durante el mandato de Theodore Roosvelt. La primera de ellas, la Food and Drug Act, que habilitaba al gobierno federal a inspeccionar alas empresas de alimentación e imponía a los fabricantes la obligación de especificar el listado de ingredientes en sus productos, fueaprobada en $1906^{10}$.Tres décadas más tarde veía la luz la Food, Drug and Cosmetic Act, que habilitaba a la Food and Drug Administartion a examinar todos los nuevos medicamentos antes de que fuesen introducidos en el mercado ${ }^{11}$.

Al margen de lo anterior, el momento histórico que marca un antes y un después en la tutela de los consumidores, es el discurso pronunciado por el presidente Kennedy en el Mensaje al Congreso de 15 de marzo de 1962 , en el que señalaba que: «los consumidores, todos nosotros por definición, representan el grupo económico más importante y se hallan interesados en casi todas las decisiones económicas, públicas o privadas. Sus gastos representan las dos terceras partes de los gastos económicos totales. Sin embargo, constituye el único grupo que no está organizado realmente y cuya opinión casi nunca es tenida en cuenta». Este mensaje ejerció una gran influencia no sólo a nivel interno sino también externo,

\footnotetext{
7 Sin embargo, la Liga de Consumidores de la ciudad de Nueva York nace con el propósito de luchar contra la explotación infantil y de las mujeres, lo hace tratando de potenciar el consumo de empresas que respeten los derechos de los trabajadores. Esta Liga, así como el movimiento asociativo de los consumidores al que se adscribe, surge muy ligado a la lucha contra la desigualdad, la discriminación y, en definitiva, la injusticia social. Vid. ESPINO HERnÁNDEZ, L. D., «Razón de ser y evolución de la protección procesal de los consumidores y usuarios», en E. González Pillado (Coord.), Resolución de conflictos en materia de consumo: proceso y arbitraje, Tecnos, Madrid, 2010, pp. 25 a 27.

${ }^{8}$ La publicación de este libro contribuyó a la sensibilización de la sociedad norteamericana sobre la necesidad de conocer los resultados de los test gubernamentales sobre calidad y precios de los productos y servicios comercializados. Al propósito inédito de revelar dichas informaciones al consumidor, sirve por vez primera la organización americana Consumer's Research, creada por uno de los autores de la obra y financiada por la suscripción a la revista mensual Consumer Bulletin, editada por la propia asociación. Vid. De León Arce, en A. De León ArCe; L. M. García García (Coords.), Derechos de los..., cit., pp. 49 a 50.

${ }^{9}$ Vid. De León Arce, en A. De León Arce; L. M. García García, (Coords.), Derechos de los..., cit., pp., íbidem.

${ }^{10}$ La promulgación de la presente Ley traía su causa del fuerte impacto generado por el libro The Jungle, publicado por UPTON SINCLAIR, en el que se describían las deplorables condiciones de trabajo en la industria del meatpacking de Chicago.

${ }^{11}$ Vid. EsPino HeRnánDEZ, L. D., «Razón de ser...», cit., p. 26.
} 
provocando que muchos Estados reorientasen sus políticas hacia una mayor protección de los consumidores.

En lo relativo al movimiento de protección de los consumidores en Europa, éste se inicia con entidad propia en la década de los sesenta en países como Francia, Alemania (entonces República Federal Alemana) y Reino Unido ${ }^{12}$. Como ejemplos de la producción legislativa desarrollada en los inicios de este movimiento de protección de los consumidores destaca, en Inglaterra, el establecimiento de la Consumer Protection Act de 1961, a la que le siguieron, entre otras leyes, la Trade Descriptions Act de 1968, la nueva Consumer Act de 1971 y la Fair Trading Act de 1973. En Francia fue desarrollada la Ley Royer, Ley del comercio y de la artesanía, de 27 de diciembre de 1973 y la Ley sobre la Protección e Información del Consumidor, de 10 de enero de 1978. Por su parte, en la entonces República Federal Alemana, el 9 de diciembre de 1976 veía la luz una ley reguladora de las condiciones generales de los contratos ${ }^{13}$. También en Suecia fueron aprobadas en esta época dos leyes destinadas a la protección del Consumidor, la Ley de 29 de junio de 1970, sobre la actuación del mercado y sobre el Tribunal del Mercado, así como la Ley de 15 de diciembre de 1975, sobre el comportamiento del mercado ${ }^{14}$. En Austria, destaca la promulgación de la Ley de Protección de los Consumidores de 8 de marzo de 1979 y en Portugal, la Ley de Defensa del Consumidor de 22 de agosto de $1981^{15}$.

Por lo que a España concierne, la evolución hacia el tránsito social al que venimos aludiendo es tardía si la comparamos con la de sus vecinos europeos, fundamentalmente por cuestiones de arrastre histórico. La devastadora Guerra Civil que asoló a España en los años treinta, así como

12 En el Reino Unido destaca con carácter previo la creación en 1844 de la primera cooperativa de consumo, la Rochdale Society of Equitable Pioneers, cuyo objetivo era evitar la especulación del intermediario. La iniciativa de su creación partió de una veintena de trabajadores que, ante la falta de recursos económicos y de los elevados precios de los productos, decidieron aunar esfuerzos bajo una cooperativa, creando un fondo común mediante el pago de cuotas para abrir una tienda de artículos de consumo doméstico. De este modo, podían satisfacer por sí mismos las necesidades que sentían como consumidores, sin tener que comprar los productos en los comercios. Vid. R. HERRERA DE LAS HERAS, «El origen constitucional de la protección de los consumidores; fundamento de Ley 44/2006», en Diario La Ley, núm. 6723, Sección Doctrina, ref. D125 , La Ley $1864 / 2007$.

${ }^{13}$ Ello no obstante, a pesar de que la Ley reguladora de las condiciones generales de los contratos ha sido la que ha gozado de mayor trascendencia, el papel de Alemania en la protección del consumidor cuenta con experiencias legislativas pioneras, como la promulgación en 1909 de la Ley de Competencia Desleal, la Ley contra prácticas restrictivas de la competencia de 1957 y la Ley sobre contrato global de viaje de 1979.

${ }^{14}$ En Suecia, así como en Finlandia, Noruega y Dinamarca, el peso de la protección de los consumidores se ha hecho recaer, fundamentalmente, en el Ombudsman (equivalente a nuestro Defensor del Pueblo) del consumidor.

15 También deben ser aquí destacadas por su relevancia, otras iniciativas legislativas emprendidas en la época, en este caso en el panorama internacional: la Ley Federal de México sobre Protección del Consumidor de 18 de diciembre de 1978; la Ley Básica japonesa sobre Protección de los Consumidores, de 30 de mayo de 1968; y la Ley de Quebec de 17 de julio de 1971 sobre Protección del Consumidor. Vid. A. ACEDo Penco, «La noción de...», cit., pp. 303 y ss. 
la subsiguiente política de autarquía y proteccionismo instaurada por el régimen franquista, han sido la principal causa de nuestro descompás en el camino hacia el desarrollo $y$, por consiguiente, de nuestro mayor retraso económico y político. Tanto es así que España no se inicia en la cultura del consumo hasta 1975, con lo que habrá que esperar hasta la promulgación de la Constitución Española de 1978, para que pueda decirse que existe en España una política directa de protección del consumidor ${ }^{16}$.

Tras la aprobación del Texto Constitucional, el principio de protección de los consumidores (art. $51 \mathrm{CE})^{17}$ obtiene la condición de principio general del Derecho ${ }^{18}$, con lo que pasa a informar, según dispone el artículo $53 \mathrm{CE}$ en su apartado tercero, la legislación positiva, la práctica judicial y la actuación de los poderes públicos ${ }^{19}$. Desde entonces empiezan a

16 Vid. Quintana CARLO, I., «La protección del consumidor en España (Aspecto comparativo con la Comunidad Económica Europea)», en Actualidad Civil, Sección Doctrina, 1987, La Ley 5341/2002, p. 801, vol. 1, pp. 1 y 2 (del documento on-line) y CorChero, M.; A. GRANDE Murillo, La protección de los consumidores. Especial referencia al Estatuto de los Consumidores de Extremadura, Thomson Aranzadi, Pamplona, 2007, pp. 22 a 36.

${ }^{17}$ Art. 51 CE: «1. Los poderes públicos garantizarán la defensa de los consumidores y usuarios, protegiendo, mediante procedimientos eficaces, la seguridad, la salud y los legítimos intereses económicos de los mismos». Este precepto es muy similar al art. 81 de la Ley portuguesa de 2 de abril de 1976, precepto que dispone expresamente que «corresponde prioritariamente al Estado: $m$ ) proteger al consumidor, especialmente mediante el apoyo a la creación de cooperativas y de asociaciones de consumidores». Sin embargo, I. QUINTANA CARLO, «La protección del...», cit., p. 22, señala que los preceptos 51 y $53.3 \mathrm{CE}$ son absolutamente innovadores en el marco europeo, pues si bien la Constitución portuguesa de 1976 establece que «corresponde prioritariamente al Estado [...] proteger al consumidor», esta protección se traduce en exclusiva en «el apoyo a la creación de cooperativas y de asociaciones de consumidores». En igual sentido, considera E. EXPósITo GómEZ, «La acción de...», cit., p. 217, pie 26, que la mención de la Constitución portuguesa de 1976 a la protección de los consumidores tenía un alcance mucho más limitado, ya que la reconocía en la parte relativa a los «Principios Generales» de la «Organización Económica», concibiéndola como un mandato genérico de la actuación pública en dicho ámbito.

18 Ello no obstante, la decisión del constituyente no fue una cuestión pacíficamente aceptada por la doctrina. Los autores contrarios a la elevación del principio de protección de los consumidores a principio informador del ordenamiento, afincados en el neoliberalismo $y$, por consiguiente, férreos defensores de la no intervención de los Poderes Públicos en cuestiones como la presente, basaron sus reticencias, principalmente, en el carácter innecesario de una medida que, a la postre, incurría en el riesgo de constreñir la libertad de mercado. Por su parte, los partidarios de la medida adoptada basaban su conformidad en la convicción de que ésta venía impuesta por el propio art. 1.1 CE, al proclamar el carácter de social y democrático de Derecho del Estado español.

19 Art. $53.3 \mathrm{CE}$ «El reconocimiento, el respeto y la protección de los principios reconocidos en el Capítulo III, informará la legislación positiva, la práctica judicial y la actuación de los poderes públicos. Sólo podrán ser alegados ante la Jurisdicción ordinaria de acuerdo con lo que dispongan las Leyes que los desarrollen». En tal sentido se ha pronunciado el Tribunal Constitucional, disponiendo a tal efecto que será preciso tenerlos presentes «en la interpretación tanto de las restantes normas constitucionales como de las leyes». Vid.STC 19/1982, de 5 de mayo (F. J. 6). 
promulgarse leyes destinadas a la defensa de los legítimos intereses de los consumidores, siendo la Ley 26/1984, de 19 de julio, General para la Defensa de los Consumidores y Usuarios (en adelante, LGDCU), la que inicia la evolución hacia una tutela colectiva de sus derechos e intereses ${ }^{20}$.

Progresivamente, en las leyes sustantivas se fueron introduciendo normas para dotar de eficacia a la protección de los derechos de los ciudadanos en su consideración de consumidores y usuarios. Es el caso de la Ley 34/1988, de 11 de noviembre, General de Publicidad, que en su artículo 25 reconoce legitimación a las asociaciones de consumidores y usuarios para solicitar la cesación o, en su caso, la rectificación de la publicidad ilícita. También incorpora tal reconocimiento el artículo 19.2 b) de la Ley 3/1991, de 1 de enero, de Competencia Desleal, que establece que las asociaciones cuyo fin estatutario sea la defensa del consumidor podrán ejercitar las siguientes acciones: la declarativa de la deslealtad del acto, la de cesación, la de remoción de los efectos y la de rectificación (acciones éstas descritas en los apartados $1^{\circ}$ a $4^{\circ}$ del art. 18). Destaca igualmente la Ley 7/1998 de 7 de abril, de Condiciones Generales de la Contratación, que a través de sus artículos 12 a 20 regula las denominadas «acciones colectivas de cesación, retractación y declarativa de condiciones generales», legitimando a los efectos de su interposición, entre otras, a las «asociaciones de consumidores y usuarios legalmente constituidas y que tengan estatutariamente encomendada la defensa de éstos» ${ }^{21}$.

Tal y como señala R. BERCOVITZ; J. SALAS, (Coords.), Estudios jurídicos sobre protección de los consumidores, Tecnos, Madrid, 1987, p. 29, la redacción del precepto transcrito en su segunda frase puede inducir a error, pues de ella pudiera desprenderse que los principios reconocidos en el Capítulo tercero no podrán ser invocados si no cuentan con apoyo expreso en una ley; cuando es evidente -de conformidad con la primera fraseque no necesitan el citado amparo legal. Lo que ocurre, como aclara este autor, es que la invocación tendrá un valor distinto según tenga apoyo expreso en una ley aplicable al caso concreto o se trate simplemente de la invocación de un principio constitucional, que, en cuanto tal, ha de ser tenido en cuenta también tanto por los tribunales como por los órganos de la Administración.

20 Con carácter previo, la crisis originada en 1981 por la intoxicación masiva por consumo de aceite de colza desnaturalizado tuvo como desencadenante la aprobación del RD $1945 / 1983$, de 22 de junio, por el que se regulan las infracciones y sanciones en materia de defensa del consumidor y de la producción agroalimentaria y la reforma de la Sección Segunda, Capítulo II, Título V, del Libro II del Código Penal (arts. 341 a 348 bis «Delitos contra la salud y el medio ambiente»), por la LO 8/1983, de 25 de junio, de Reforma Urgente y Parcial del Código Penal.

${ }^{21}$ También incorporan medidas procesales destinadas a la facilitación de los procesos a la materia referidos: la Ley 26/1991, de 21 de noviembre, sobre contratos celebrados fuera de los establecimientos mercantiles; la Ley 7/1995, de 23 de marzo, de Crédito al Consumo, la Ley 7/1996, de 15 de enero, de Ordenación del Comercio Minorista; la Ley 7/1998, de 13 de abril, sobre condiciones generales de la contratación; y la Ley 28/1998, de 13 de julio, de Venta a Plazos de Bienes Muebles.

Con carácter posterior a la LEC del año 2000 podemos citar, entre otras, las siguientes leyes especiales en materia de protección de los consumidores: la Ley 40/2002, de 14 de noviembre, reguladora del contrato de aparcamiento de vehículos; la Ley 23/2003, de 11 de julio, de garantías en la venta de bienes de consumo; la Ley 44/2006, de 29 de diciembre, de mejora de la protección de los consumidores y usuarios; la Ley $1 / 2007$, de 
Por su parte, en el plano del Derecho Procesal Civil no se aprecia una progresión pareja a la experimentada en el ámbito del Derecho material. La Ley de Enjuiciamiento Civil de 1881, inspirada en principios liberales, era completamente ajena a la existencia de nuevas necesidades de tutela, y el proceso en su seno articulado (construido sobre la base de relaciones jurídicas puramente individualistas), obstruía el acceso de los consumidores a la justicia, por encontrarse éstos con un obstáculo insalvable, el de la legitimación ${ }^{22}$.

Con la aprobación de la LOPJ de 1985 se emprendió una loable pero a todas luces insuficiente iniciativa en este sentido, al establecer su artículo 7.3 que «Los Juzgados y Tribunales protegerán los derechos e intereses legítimos, tanto individuales como colectivos, sin que en ningún caso pueda producirse indefensión los derechos e intereses legítimos, tanto individuales como colectivos. Para la defensa de estos últimos se reconocerá la legitimación de las corporaciones, asociaciones y grupos que resulten afectados o que estén legalmente habilitados para su defensa $y$ promoción»; y es que para que esta norma tuviese eficacia práctica resultaba imprescindible un desarrollo legislativo que no se llevó a cabo.

La lacra que nuestro arcaico sistema procesal civil supuso para la adecuación entre avance social y Derecho, tardó todavía varios años en comenzar a ser superada. Fue de la mano de la Ley de Enjuiciamiento Civil 1/2000 cuando se comenzó a recorrer un camino del que todavía queda largo trecho, pues pese a que son muchos los pasos dados, el modo en que la regulación procesal se ha llevado a cabo no ha sido la más acertada.

16 de noviembre, por la que se aprueba el Texto Refundido de la Ley General de los Consumidores y Usuarios y otras Leyes complementarias.

22 Esta desprotección del consumidor en el plano del proceso civil, por suerte, no constituía una constante en los restantes órdenes jurisdiccionales. En la Ley de Enjuiciamiento Criminal de 1882, tal protección se tradujo en el reconocimiento de la acción popular. Por su parte, esta acción pública se fue ulteriormente ampliando a otros sectores del ordenamiento jurídico. En el ámbito administrativo, constituyen obligada referencia la cita del artículo 16 del Decreto 833/1975, de 6 de febrero, sobre protección del medio ambiente atmosférico; el artículo 8.2 de la Ley 16/1985, de 25 de junio, del Patrimonio Histórico Nacional; artículo 109 de la Ley de 22/1988, de 28 de julio, de Costas, y artículo 304 de la Ley del Suelo, aprobada por Real Decreto Legislativo 1/1992, de 26 de junio, precepto que ha dejado expresamente en vigor la Ley 6/1998, de 13 de abril.

Igualmente, el artículo 31.1 de la Ley 30/1992, de 26 de noviembre, del régimen jurídico de las administraciones públicas y del procedimiento administrativo común, reconoce como interesados, en el procedimiento administrativo, a los «titulares de derechos o intereses legítimos, individuales o colectivos» $\mathrm{y}$, en el orden jurisdiccional contencioso administrativo, esta legitimación colectiva se encuentra reconocida en los artículos 18 y 19 de la Ley 29/1998, de 13 de julio.

Incluso la Ley de procedimiento Laboral extiende la legitimación de los sindicatos, en su artículo 20.1, para actuar en el proceso en nombre e interés de los trabajadores afiliados, estableciendo el art. 151 que «se tramitarán a través del presente proceso las demandas que afecten a intereses generales de un grupo genérico de trabajadores y que versen sobre la aplicación e interpretación de una norma estatal, convenio colectivo, cualquiera que sea su eficacia, o de una decisión o práctica de empresa» 


\section{LA NOCIÓN DE CONSUMIDOR EN EL DERECHO DE LA UNIÓN EUROPEA}

\subsection{En el Derecho Primario}

El concepto de consumidor es a día de hoy fundamental en el Derecho de la Unión Europea, pues la protección de los consumidores constituye uno de los ejes centrales de su política legislativa. Ello no obstante, remontándonos a los primeros momentos en la andadura de la Comunidad Europea, comprobamos que la necesidad de proteger al consumidor como parte más débil de la relación económica no fue siempre una de sus prioridades.

Los objetivos de la primera etapa de la Comunidad se concentraron cuasi exclusivamente en la construcción del mercado común europeo, centrándose, fundamentalmente, en la libre circulación de personas, de capitales, de mercancías y de servicios. Tanto es así, que el Tratado de Roma de $1957^{23}$, constitutivo de la Comunidad Económica Europa, no contemplaba disposiciones específicas destinadas a la protección de los consumidores ni, en consecuencia, una noción de consumidor ${ }^{24}$.

La indiferencia hacia el consumidor como parte débil de la relación económica se explica porque en el momento de elaboración del Texto Constitutivo no estaba asentado el movimiento socioeconómico y políticojurídico propio de la sociedad del consumo en masa, encontrándose aún vigente la sensación de bienestar económico en Europa. Existía a la sazón el convencimiento de que el mercado podía por sí mismo colmar las necesidades del consumidor con sólo asentarse sobre una base concurrencial ${ }^{25}$, imperando la convicción de que la protección normativa era innecesaria ${ }^{26}$.

${ }^{23}$ El art. 2 del Tratado de Roma de 1957 establecía que «la Comunidad tendrá por misión promover, mediante el establecimiento de un mercado común y la aproximación progresiva de las políticas de los Estados miembros, un desarrollo armonioso de las actividades económicas en el conjunto de la Comunidad, un desarrollo continuo y equilibrado, una mayor estabilidad, una creciente elevación del nivel de vida y un estrechamiento de las relaciones entre los Estados miembros».

24 Tal y como advierte T. BouRgoigniE, Elementos para una teoría del Derecho del consumo, Departamento de Comercio, Consumo y Turismo del Gobierno Vasco, Vitoria, 1994, pp. 1774 y ss., únicamente contemplaba una concepción «productivista» de los intereses de los consumidores en el mercado común.

${ }^{25}$ Cfr. J. PAgAdor LóPEZ, La Directiva Comunitaria sobre cláusulas contractuales abusivas, Madrid, 1998, p. 16. En el mismo sentido se expresa F. ESTEBAN DE LA RoSA, La protección de..., cit., p. 47. A su vez, como explica PINEDo, E., La protección de.., cit. p. 49, la CEE ni tan siquiera tenía reconocida la competencia en orden a procurar la protección de los consumidores, pues la Comunidad, en contraposición a lo que sucede respecto de los Estados miembros, no tiene competencias generales sino tan sólo de atribución.

${ }^{26} \mathrm{El}$ germen de la política de protección de los consumidores lo encontramos en el Programa Preliminar de la Comunidad Económica Europea para una Política de Protección e Información a los consumidores, aprobado por Resolución del Consejo de 14 de abril de 1975. Este primer Programa, construido sobre la idea de que «la mejora cualitativa de las condiciones de vida es una de las misiones de la seguridad y de los intereses económicos del consumidor», recoge una declaración solemne de los derechos que deben asistir a todo ciudadano en cuanto consumidor: protección de su salud y de su seguridad; protección de sus intereses económicos; reparación de los daños que se le causen; a la información y a la educación; y derecho a la representación o a ser oído.Poco después, a 
La aprobación del Acta Única Europea, firmada en Luxemburgo el 17 de febrero de 1986, introduce por primera vez en el marco de un tratado constitutivo comunitario -aunque no explícitamente ${ }^{27}$ - la defensa del consumidor, al incorporar entre sus objetivos ${ }^{28}$ : el de «asegurar al consumidor suministros a precios razonables» y el de «limitar la producción, el mercado o el desarrollo técnico en beneficio de los consumidores» ${ }^{29}$.

El Tratado de la Unión Europea (TUE), firmado en Maastricht el 7 de febrero de 1992, regula por medio del artículo 129 A de modo mucho más concreto y eficaz la protección de los consumidores, al disponer que la Comunidad contribuirá a la consecución de un alto nivel de protección de sus intereses, a través, entre otras, de medidas concretas que apoyen y complementen la política asumida por los Estados miembros a fin de proteger la salud, la seguridad y los intereses económicos de los consumidores ${ }^{30}$.

través del Segundo Programa de la Comunidad Europea para una Política de Protección e Información a los consumidores (1981), se profundiza en las medidas emprendidas en el Primer Programa y se incide sobre la importancia de incrementar el diálogo entre consumidores y productores-distribuidores.

${ }^{27}$ En los trabajos preparatorios a esta reforma del Tratado (en concreto, en el art. 57 del Proyecto de Tratado aprobado por el Parlamento Europeo el 14 de febrero de 1984, a la sazón el Proyecto Spinelli) sí figuraba la mentada referencia explícita a la protección de los consumidores, con indicación expresa de los ámbitos específicos en que la actuación de las instituciones comunitarias estaría legitimada. Cfr. E. EXPósITo GómEZ, «La acción de la Unión Europea en la protección de los consumidores», en A. OLESTI RAYO, (Coord.), La Incidencia del Tratado de Lisboa en el ejercicio de las competencias autonómicas, Institut d'Estudis Autonòmics, Seminarios, Barcelona, 2009, pp. 205 a 206.

${ }^{28}$ Art. 100 A: «La Comisión, en sus propuestas previstas en el apartado 1 referentes a la aproximación de las legislaciones en materia de salud, seguridad, protección del medio ambiente y protección de los consumidores, se basará en un nivel de protección elevado, teniendo en cuenta especialmente cualquier novedad basada en hechos científicos. En el marco de sus respectivas competencias, el Parlamento Europeo y el Consejo procurarán también alcanzar ese objetivo». Tal y como indica a este respecto J. LETE ACHIRICA, «La armonización de las legislaciones europeas sobre protección de los consumidores a la luz del derecho comunitario», en Actualidad Civil, Sección Doctrina, 1998, Ref. IX, p. 183, vol. 1, La Ley, dicho artículo así como el incorporado por el Acta Única Europea constituyen hoy la base legal de intervención legislativa a nivel comunitario, pero apenas pueden apreciarse todas sus implicaciones sin estudiar la copiosa jurisprudencia del Tribunal de Justicia en materia de eficacia e interpretación del Derecho comunitario.

29 En el mismo año se elabora el Tercer Programa comunitario -contenido en la Resolución del Consejo de 23 de junio de 1986, relativa a la reorientación futura de la política de la Comunidad Económica Europea para la protección y el fomento de los intereses de los consumidores-, en el que el Consejo acepta los fundamentos y hace suyos los objetivos del programa «Nuevo impulso a la política de protección de los consumidores». Sólo tres años más tarde se elabora el Cuarto Programa comunitario sobre consumo, centrándose en el fomento de la seguridad general de los productos y de los servicios, así como en la mejora de la información sobre la calidad de los productos y servicios.

${ }^{30}$ Para BouRgoIgNIE, hasta el Tratado de Maastricht no se puede hablar de una auténtica política de consumo a nivel comunitario, en T. BouRGOIGNIE, «Droit et politiques communautaires de la consommation: de Rome a Ámsterdam», REDC, núm. 3, 1997, p. 194. En igual sentido se pronuncia EXPósito GómEZ, E., «La acción de...», cit., p. 36. 
El Tratado de Ámsterdam, firmado el 2 de octubre de 1997, sin desviarse de las anteriores orientaciones, supone un paso hacia adelante en la acción comunitaria desarrollada hasta la fecha ${ }^{31}$. La reforma que emprende del TCE supone un nuevo impulso a la política de protección de los consumidores, salvando algunas de las deficiencias de la anterior redacción del artículo 129 A (ahora art. 153) y procediendo a la enumeración de los derechos del consumidor ${ }^{32}$.

La regulación introducida en el TCE por el Tratado de Ámsterdam se mantiene prácticamente inalterada en el Tratado de Niza, firmado el 26 de febrero de 2001, destacando como principal novedad el reconocimiento explícito de los consumidores como grupo con representación propia y directa en el Consejo Económico y Social (art. 275 TCE). Se enmienda así su omisión en la enumeración de las categorías sociales y económicas que lo integraban ${ }^{33}$.

Por último, entre las medidas que incorpora el Tratado de Lisboa, firmado el 13 de diciembre de 2007, destaca el sistema de reparto competencial que diseña entre los Estados y la Unión, distinguiendo entre «categorías y ámbitos de competencias de la Unión» y calificándolas como exclusivas, compartidas y de coordinación. La protección de los consumidores pasa a formar parte de uno de los ámbitos materiales de competencia compartida entre la Unión y los Estados (artículo 4.2.f TFUE) ${ }^{34}$. Según el artículo 2 TFUE, por medio de dicha competencia «la Unión y los Estados miembros podrán legislar y adoptar actos

${ }^{31}$ Vid. a este respecto J. GuILlÉn CARAMÉS, «El marco jurídico de la política comunitaria de protección de los consumidores», en Revista de Derecho de la Unión Europea, núm. 5, $2^{\circ}$ semestre 2003.

32 «1. Para promover los intereses de los consumidores y garantizarles un alto nivel de protección, la Comunidad contribuirá a proteger la salud, la seguridad y los intereses económicos de los consumidores, así como a promover su derecho a la información, a la educación y a organizarse para salvaguardar sus intereses.

1. Al definirse y ejecutarse otras políticas y acciones comunitarias se tendrán en cuenta las exigencias de la protección de los consumidores.

2. La Comunidad contribuirá a que se alcancen los objetivos a que se refiere el apartado 1 mediante:

a) Medidas que adopte en virtud del artículo 95 en el marco de la realización del mercado interior;

b) Medidas que apoyen, complementen y supervisen la política llevada a cabo por los Estados miembros.

3. El Consejo, con arreglo al procedimiento previsto en el artículo 251 y previa consulta al Comité Económico y Social, adoptará las medidas mencionadas en la letra b) del apartado 3.

4. Las medidas que se adopten en virtud del apartado 4 no obstarán para que cada uno de los Estados miembros mantenga y adopte medidas de mayor protección. Dichas medidas deberán ser compatibles con el presente Tratado. Se notificará a la Comisión».

${ }^{33}$ E. EXPósito GómeZ, «La acción de...», cit., pp. 214 a 215.

34 Ello no obstante, comoquiera que este art. 4.2 TFUE no especifica en qué concretos ámbitos de la protección de los consumidores tiene atribuida competencia la Unión Europea, la doctrina se ha planteado si ha de extenderse su competencia a aquellos sectores de la defensa de este colectivo que no inciden en el mercado interior. La opinión mayoritaria, sin embargo, considera que el art. 169 TFUE, en especial su apdo. 2, no avala semejante interpretación. 
jurídicamente vinculantes en dicho ámbito. Los estados miembros ejercerán su competencia en la medida en que la Unión no haya ejercido la suya». En este sentido, el Tratado de Lisboa no hace más que elevar al rango de Derecho originario lo que ya había sentenciado el Tribunal de Justicia en esta materia desde la conocida STJCE de 20 febrero $1979^{35}$, asunto Cassis Dijon.

Ello no obstante, a pesar de las disposiciones que han sido incorporadas al Derecho originario para favorecer la protección de los consumidores, no encontramos en los Tratados constitutivos de la Unión Europea definición alguna de consumidor.

\subsection{En el Derecho Convencional}

En el Derecho Convencional, el primer texto que incorpora el concepto de consumidor es el Convenio de Bruselas de $1968^{36}$-relativo a la competencia judicial y a la ejecución de resoluciones judiciales en materia civil y mercantil ${ }^{37}$-. Lo hace por medio de su artículo $13^{38}$, en el que regula un foro de competencia especial para los contratos celebrados «por una persona para un uso que pudiera considerarse ajeno a su actividad profesional, en lo sucesivo denominada el consumidor» ${ }^{39}$.

35 STJCE de 20 febrero 1979, asunto C-120/78, «Rewe-Zentral AG C. Bundesmonopolverwaltung für Branntwein», también conocido con el asunto «Cassis Dijon». Esta resolución admite la aplicación de las legislaciones nacionales en materia de protección de los consumidores aun cuando éstas pudieran incidir negativamente en el comercio intracomunitario. EI TJCE considera a estos efectos que la legislación favorable al consumidor del país de destino podría ser aplicada en la medida en que la protección del consumidor constituye una exigencia imperativa de interés general que justifica la limitación a las libertades de circulación. El Alto Tribunal reconoce así de manera absolutamente novedosa el menester de armonizar las exigencias de la política de libre circulación de mercancías y la destinada a la promoción efectiva de los intereses de los consumidores. Con ello, se reconocía a la postre que la defensa de los consumidores constituye un objetivo político específico de los Estados miembros, susceptible de justificar la presencia de obstáculos a la política europea de libre cambio.

36 La sección $4^{a}$ del Título II se denominaba «Competencia en materia de venta y préstamos a plazos», sin que existiera una referencia expresa a los consumidores ni siquiera en el informe JENARD (DOCE C 189, de 28 de julio de 1990, pp. 122 a 179).

37 El informe SCHLOSSER (publicado en el DO C 59 de 1979, p. 71; texto en español en DO C 189 de 1990, p. 184, apdos. 153 a 161, pp. 117 a 120, elaborado a propósito de dicho Convenio, relataba cómo la creciente preocupación en torno a la protección de los consumidores en las transacciones internacionales hacía necesaria la ampliación de la Sección cuarta del Título II, añadiendo «una sección relativa a la competencia en materia de contratos celebrados por los consumidores, especificando que, en el futuro, la protección particular valdrá únicamente para el consumidor final y no se referirá a las personas que actúen en el ejercicio de su actividad profesional».

38 Hoy art. 15 del Reglamento (CE) núm. 44/2001 del Consejo, de 22 de diciembre de 2000, relativo a la competencia judicial, el reconocimiento y la ejecución de resoluciones judiciales en materia civil y mercantil.

${ }^{39}$ La definición que acaba de ser reproducida no se encontraba en su redacción original, se introduce con ocasión del Convenio de Luxemburgo de 9 de octubre de 1978, relativo a la adhesión de Dinamarca, Irlanda y Reino Unido al Convenio de Bruselas de 1968, tomándose su tenor de los trabajos preparatorios del Anteproyecto del Convenio de Roma de 1980. El Convenio de Roma de 1980 disponía por medio de su art. 5 que: «El presente artículo se aplicará a los contratos que tengan por objeto el suministro de 
De acuerdo con la definición reproducida supra, para identificar la presencia de una adquisición de consumo habrá que fijar la atención en el uso, profesional o privado, que del bien o servicio haga el adquirente ${ }^{40}$, de modo que su interpretación literal pudiera llevar a considerar como consumidores a quienes actuando en el marco de su actividad profesional adquieran bienes para un uso privado ${ }^{41}$. Sin embargo, esta última no fue la interpretación seguida por el TJCE, que ha asumido una interpretación restringida del concepto convencional de consumidor ${ }^{42}$. Así, la STJCE de 19 de enero $1993^{43}$, asunto Shearson Lehman Hutton, en respuesta a la cuestión prejudicial planteada por el Tribunal Supremo alemán sobre la interpretación de los párrafos primero y segundo del artículo 13 del Convenio de Bruselas de $1968^{44}$, manifiesta que «De la redacción y de la función de estas disposiciones resulta que éstas sólo se refieren al consumidor final privado que no participe en actividades comerciales o profesionales» ${ }^{45}$. Por otro lado, en la STJCE de 3 de junio $1997^{46}$, asunto

bienes muebles corporales o de servicios a una persona, el consumidor, para un uso que pudiere considerarse ajeno a su actividad profesional».

40 A este respecto señala CARrillo Pozo, L. F., «Comentarios al art. 13», en A. L. CALvo CARAVACA, (Ed.), Comentario al Convenio de Bruselas relativo a la competencia judicial y a la ejecución de resoluciones judiciales en materia civil y mercantil, Universidad Carlos III, Madrid, 1994, pp. 273 a 274, que existen tres tipos de definiciones de consumidor que se diferencian según se ponga el acento en la naturaleza del destino de los bienes o servicios que se adquieran, en la naturaleza no profesional de la actividad de su adquirente en el momento de la conclusión del contrato o, por último, en la concurrencia de los dos criterios señalados. Así, por lo que a este autor respecta, la definición que incorpora el art. 13 del Convenio, se basaría en el primero de los antedichos criterios, a la sazón, el correspondiente a la naturaleza del destino de aquello que se adquiera.

${ }^{41}$ Tal y como señala F. ESTEBAN DE LA ROSA, La protección de..., cit., p. 50, «la referencia a la actividad profesional no lo es a título de elemento adicional, sino que forma parte del requisito relativo al uso del bien o servicio objeto del contrato».

${ }^{42} \mathrm{Al}$ respecto de la interpretación del concepto convencional de consumidor, tal y como explica F. ESTEBAN DE LA ROSA, La protección de..., cit., p. 48, cabe aclarar, tal y como lo hace este autor, que si bien es cierto que este órgano jurisdiccional es competente en orden a interpretar el convenio de Bruselas en virtud del protocolo de Luxemburgo de 3 de junio de 1971, carece de competencias interpretativas respecto de las disposiciones del Convenio de Roma de 1980. Ello no obstante, la íntima relación entre este último y el Convenio de Bruselas justifica que las interpretaciones del TJCE a propósito del segundo se hagan extensibles también al primero.

${ }^{43}$ STJCE de 19 de enero de 1993, asunto C-89/91, «Shearson Lehmann Hutton Inc. C. TVB Treuhandgesellschaft für Vermögensverwaltung und Beteiligungen $\mathrm{mbH}$.», (en adelante, sentencia Shearson Lehman Hutton).

44 Modificado por el Convenio de 9 de octubre de 1978, relativo a la adhesión de Dinamarca, de Irlanda y del Reino Unido de Gran Bretaña e Irlanda del Norte.

${ }^{45}$ Apdo. 22 sentencia Shearson Lehman Hutton.

Cabe señalar además la existencia de una experiencia jurisprudencial previa a la modificación del Convenio de Bruselas de 1968, esto es, anterior a la incorporación de la definición de consumidor a la que hemos hecho mención. Ésta viene referida a la STJCE de 21 de junio 1978, asunto C-150/77, «Bertrand c. Paul Ott KG». En aquella ocasión, se trataba de determinar si un contrato de compraventa a plazos de maquinaria, celebrado entre dos sociedades, constituía una venta a plazos en el sentido del art. 13 CB. Con tal propósito fue sometida al TJCE una cuestión prejudicial que, en definitiva, trataba de decidir si los contratos entre profesionales podían beneficiarse del privilegio de elección de fuero contemplado por la norma. En este caso resolvió el Alto Tribunal con la 
Benincasa, en contestación a la cuestión prejudicial planteada por el Tribunal Superior Regional Civil y Penal de Múnich, sobre la interpretación de los mismos preceptos del Convenio, pero en este caso en relación al contrato celebrado para el ejercicio de una actividad profesional futura, estable que «las disposiciones protectoras del consumidor como parte económicamente más débil sólo engloban los contratos para satisfacer las propias necesidades de consumo privado de un individuo ${ }^{47}{ }^{4}$, con lo que desligaba la actuación del consumidor de la actividad comercial sin perjuicio de que ésta fuese presente o futura ${ }^{48}$.A su vez, en la STJCE de 20 de enero $2005^{49}$, asunto Gruber, en la que resolvía un supuesto de destino mixto - parcialmente profesional, parcialmente privado ${ }^{50}$, el TJCE manifestaba que las normas protectoras de los consumidores podrían ser únicamente aplicables en el supuesto de que el uso profesional del bien o servicio fuese marginal, hasta el punto de tener un papel insignificante en el contexto global de la operación ${ }^{51}$.

\subsection{En el Derecho Derivado}

En el ámbito del Derecho Derivado de la Unión Europea, aunque no existe una única noción de consumidor, ya que cada Directiva incorpora la suya propia ${ }^{52}$, se aprecia el claro predominio de aquélla que se refiere a éste como «toda persona física que actúa con un propósito o fin ajeno a

negativa, optando por una interpretación restrictiva $y$, por consiguiente, reservando dicho privilegio a los compradores que, por la debilidad de su condición económica frente al vendedor, estuviesen necesitados de protección.

${ }^{46}$ STJCE de 3 de junio 1997, asunto C-269/95, «Francesco Benincasa C. Dentalkit Srl», (en adelante, sentencia Benincasa).

47 En este caso, el asunto sometido al TJCE versaba sobre la posibilidad de invocar los foros de la sección cuarta del Título II del convenio de Bruselas por el tomador de un contrato de franquicia. El Tribunal negó que un franquiciado pueda ampararse en las normas de protección de los consumidores para defender sus intereses, pues el contenido de dicho contrato implica para ambas partes la realización de actividades de carácter empresarial o profesional.

${ }^{48}$ Apdo. 16 sentencia Benincasa.

49 STJCE de 20 de enero 2005, asunto C-464/01, «Johann Gruber c. Bay Wa AG».

50 Puede verse comentada esta sentencia en G. ROMERO GARCÍA-MORA, «En torno al concepto de «consumidor» en el Derecho Comunitario. A propósito de la STJCE Gruber vs. Bay Wa», en Actualidad civil, núm. 22, Sección A Fondo, Quincena del 16 al 31 Dic. 2005, p. 2704, La Ley 5132/2005.

${ }^{51}$ Apdo. 39 Sentencia Gruber. En el presente caso, el Sr. Gruber, agricultor austríaco y titular de una granja en las proximidades de la frontera alemana compra a la empresa alemana «Bay Wa, AG» un lote de tejas con el objeto de techar su granja (edificio este que destina, en su mayoría, a su propia vivienda).

52 Romero García-MorA, G., «En torno al...», cit., p. 5, ha sostenido a este respecto, (aunque no sólo referido a la definición de consumidor en el Derecho Derivado, sino como reflexión final tras el análisis de las definiciones comunitarias de consumidor), que la noción comunitaria de consumidor es difusa y eventualmente multiforme, y ello, por cuanto la noción de consumidor en este ámbito no puede formularse en abstracto, siendo necesario tomar como referencia para su definición las normas de Derecho de obligaciones y contratos, concluyendo así que se trata de un concepto de derivación material. 
su actividad profesional> ${ }^{53}$. También es ésta la definición que ha incorporado -aunque con destacables diferencias que posteriormente serán analizadas- el Texto Refundido de la Ley General para la Defensa de los Consumidores y Usuarios (en adelante, TRLGDCU).

La Directiva 1985/577/CEE, de 20 de diciembre de 1985, relativa a la protección de los consumidores en los contratos negociados fuera de los establecimientos mercantiles, fue la pionera en orden a incorporar la fórmula negativa de consumidor a la que se ha hecho mención. En su artículo 2 estable que será considerada consumidora «toda persona física que, para las transacciones amparadas por la presente Directiva, actúe para un uso que pueda considerarse como ajeno a su actividad profesional». Sucesivamente, en un sentido semejante, la mayor parte de las Directivas fueron reiterando la idea de que el consumidor, para obtener tal consideración, ha de actuar al margen de su actividad empresarial ${ }^{54}$.

Ello no obstante, algunas directivas han acogido un concepto de consumidor distinto al que aludimos anteriormente. Es el caso, por un lado, de la Directiva 90/314/CEE del Consejo, de 13 de junio de 1990, relativa a los viajes combinados, las vacaciones combinadas y los circuitos

\footnotetext{
53 Tal y como señala ESTEBAN DE LA ROSA, F.,La protección de..., cit., p. 61, nota al pie. 134, «la terminología empleada por las Directivas no es idéntica, hablándose a veces de "fines", otras de "propósitos", y otras de "uso". Sin embargo, no parece que de esta desigualdad quepa extraer verdaderas diferencias de tratamiento jurídico en dependencia de la expresión utilizada, resultando razonable entender que con unas y otras expresiones se está aludiendo a la misma idea».

${ }^{54}$ Así las cosas, para las siguientes directivas es consumidor, toda persona física o cualquier persona física que: según la Directiva 93/13/CEE, de 5 de abril de 1993, sobre cláusulas abusivas, «actúe con un propósito ajeno a su actividad profesional»; la Directiva 98/6/CE, de 16 de febrero de 1998, en materia de indicación de precios de los productos ofrecidos a los consumidores, «compre un producto con fines ajenos a su actividad comercial o profesional»; la Directiva 99/44/CE, de 25 de mayo de 1999, relativa a la venta y garantía de bienes de consumo, «actúa con fines que no entran en el marco de su actividad profesional»; las Directivas 2000/31/CE, de 8 de junio de 2000, sobre el comercio electrónico y 2005/29/CE, de 11 de mayo de 2005, relativa a las prácticas comerciales desleales de las empresas en sus relaciones con los consumidores en el mercado interior, «actúa con un propósito ajeno a su actividad económica, negocio o profesión»; para la Directiva 2002/65/CE, de 23 de septiembre de 2002, relativa a la comercialización a distancia de servicios financieros destinados a los consumidores, «actúe con un propósito ajeno a su actividad económica, negocio o profesión»; para la Directiva 2008/48/CE, de 23 de abril de 2008, relativa a los contratos de crédito al consumo, por la que se deroga la Directiva 87/102/CEE, «actúa con fines que están al margen de su actividad comercial o profesional»; la Directiva 2008/122/CE, de 14 de enero de 2009, relativa a la protección de los consumidores respecto a determinados aspectos de los contratos de aprovechamiento por turno de bienes de uso turístico, de adquisición de productos vacacionales de larga duración, de reventa y de intercambio, «que actúe con fines ajenos a su actividad comercial, empresa, oficio»; la Directiva 2011/38/UE, de 25 de octubre de 2011, sobre los derechos de los consumidores, define en la misma línea al consumidor como aquél que «actúa con un propósito ajeno a su actividad comercial, empresa, oficio o profesión»; y para la Directiva 2013/11/UE, del Parlamento Europeo y del Consejo, de 21 de mayo de 2013, relativa a la resolución alternativa de litigios en materia de consumo «que actúe con fines ajenos a sus actividades comerciales o empresariales, a su oficio o a su profesión».
} 
combinados, que en su artículo 2.4 define al consumidor como «/a persona que compra o se compromete a comprar el viaje combinado («el contratante principal»), la persona en nombre de la cual el contratante principal se compromete a comprar el viaje combinado («los demás beneficiarios») o la persona a la cual el contratante principal u otro beneficiario cede el viaje combinado («cesionario»)». Y, por otro, la Directiva 85/374/CEE del Consejo, de 25 de julio de 1985, relativa a la aproximación de las disposiciones legales, reglamentarias y administrativas de los Estados miembros en materia de responsabilidad por los daños causados por productos defectuosos, puesto que en este caso, sustituye el concepto de consumidor por el de perjudicado ${ }^{55}$.

Al margen de las anteriores, la noción mayoritaria incide sobre la necesidad de que el consumidor, para ser considerado como tal, ha de actuar con un fin ajeno a «su» actividad profesional, de lo que podría desprenderse que podría ser consumidor cuando actúe con fines comerciales desligados de su oficio o profesión.

A los efectos de dar respuesta a la cuestión aquí planteada, apreciamos una evolución en la jurisprudencia del Tribunal de Luxemburgo, que ha pasado de asumir un criterio muy restrictivo a otro mucho más flexible. De este modo, si bien en sus primeras resoluciones, a las que nos referiremos seguidamente, considera que el acto de consumo debe desvincularse por completo de la actividad comercial, sea o no la propia del adquirente, en los últimos tiempos ha venido considerando que el consumidor, para ser considerado como tal, ha de actuar únicamente al margen de la actividad empresarial que le es propia.

De entre sus primeros pronunciamientos en la materia, conviene recordar la STJCE de 14 de marzo de $1991^{56}$, asunto Patrice di Pinto, en la que se pronunciaba acerca de la posibilidad de que un comerciante que había celebrado en su domicilio un contrato de publicidad sobre un fondo de comercio, pudiera ser considerado consumidor a los efectos de la Directiva 85/577, sobre contratos celebrados fuera de establecimiento mercantil.

En este caso, a pesar de la que la Comisión se había pronunciado a favor de que un comerciante pudiera disfrutar, bajo determinadas circunstancias, de la protección establecida por la Directiva a favor del

55 Por su parte, ciertas Directivas se han abstenido de recoger su propio concepto de consumidor, es el caso de la Directiva 84/450/CEE reguladora de la publicidad engañosa; la Directiva 85/734/CEE sobre responsabilidad por los daños causados por productos defectuosos; la Directiva 2001/95/CE relativa a la seguridad general de los productos; la Directiva 87/250/CEE reguladora de la indicación del grado alcohólico volumétrico en las etiquetas de las bebidas alcohólicas destinadas al consumidor final; la Directiva 94/11/CE, relativa a la aproximación de las disposiciones legales, reglamentarias y administrativas de los Estados miembros en relación con el etiquetado de los materiales utilizados en los componentes principales del calzado destinado a la venta al consumidor; la Directiva 89/107/CEE relativa a los aditivos alimentarios; la Directiva 89/397/CEE relativa al control de los productos alimenticios o el Reglamento núm. 852/2004 relativo a la higiene de los productos alimenticios.

56 STJCE 14 de marzo 1991, asunto C-361/89, «Procedimiento penal entablado c. Patrice Di Pinto», (en adelante, sentencia Patrice Di Pinto). 
consumidor $^{57}$, el Tribunal de Luxemburgo se opuso a tal razonamiento. En su opinión, «lo más lógico, efectivamente, es creer que un comerciante, medianamente sagaz, conoce el valor de su fondo y el de cada uno de los actos que necesita su venta, de modo que si contrae un compromiso no pueda ser de manera inconsiderada y únicamente bajo el efecto de la sorpresa»; de manera que «el comerciante que recibe una visita a domicilio con el fin de celebrar un contrato de publicidad relativo a la venta de su fondo de comercio no debe ser considerado como un consumidor protegido por la Directiva». En definitiva, el TJCE resuelve que tales contratos con otros empresarios «constituyen actos de gestión realizados para satisfacer necesidades que no son las necesidades familiares o personales del comerciante» ${ }^{58}$.

En relación con la misma Directiva cabe destacar también la STJCE de 17 de marzo de $1998^{59}$, asunto Dietzinger, en la que se pronuncia acerca de la delimitación del concepto de consumidor en las obligaciones de fianza. En concreto, la cuestión venía referida a la posibilidad de considerar consumidor a un particular que había concluido un contrato de fianza con el objeto de garantizar la devolución de un préstamo para consumo empresarial ajeno. En este supuesto, siguiendo la línea ya marcada con anterioridad, establece que la Directiva «no limita su ámbito de aplicación en función de la naturaleza de los bienes o servicios objeto del contrato, siempre que tales bienes o servicios estén destinados al consumo privado» ${ }^{60}$. Y añade que el concepto de consumidor a efectos de dicha Directiva debe interpretarse en el sentido de que «un contrato de fianza celebrado por una persona física que no actúe en el marco de una actividad profesional está excluido del ámbito de aplicación de la Directiva cuando garantiza el reembolso de una deuda contraída por otra persona que actúe en el marco de su actividad profesional» ${ }^{61}$.

Tal y como se extrae de los pronunciamientos del TJCE reproducidos, el concepto de consumidor debe entenderse desligado de la actividad empresarial, constituya o no la propia profesión del adquirente. Sin embargo, como tuvimos ocasión de avanzar anteriormente, en los últimos tiempos se ha advertido un cambio de rumbo en la jurisprudencia del TJUE, de modo que la anterior afirmación merece nuevos matices.

Así se desprende de la STJUE, de 9 de julio de $2015^{62}$, asunto Bucura, en la que establece que la persona física que actúa como codeudora debe

57 En concreto, la Comisión condicionaba la posibilidad de que un comerciante pudiese ostentar la consideración de consumidor a la concurrencia de las siguientes circunstancias: que la venta fuera ajena a su actividad profesional normal; que la iniciativa de la transacción no hubiera procedido de la persona que deseaba vender su fondo de comercio; y que dicho vendedor careciese de experiencia en el momento de la venta.

${ }^{58}$ Apdo. 16 sentencia Patrice Di Pinto.

59 STJCE de 17 de marzo 1998, asunto C-45/96, «Bayerische Hypotheken- und Wechselbank AG c. Edgard Dietzinger», (en adelante, sentencia Dietzinger).

${ }^{60}$ Apdo. 18 sentencia Dietzinger.

${ }^{61}$ Apdo. 23 sentencia Dietzinger.

${ }^{62}$ STJUE de 9 de julio de 2015, asunto C-348/14, «Maria Bucura C. SC Bancpost SA», (en adelante, sentencia Bucura). 
ser considerada consumidor siempre que actúe para un fin ajeno a «su» actividad empresarial. En la misma línea, la STJUE de 3 de septiembre de $2015^{63}$, asunto Costea, concluye que una persona física que ejerce la abogacía y celebra con un banco un contrato de crédito, sin que en él se precise el destino del crédito, puede ser considerado «consumidor» con arreglo a la Directiva 93/13/CEE del Consejo, de 5 de abril de 1993, sobre las cláusulas abusivas en los contratos celebrados con consumidores (en adelante, Directiva 93/13/CEE), cuando dicho contrato no esté vinculado a la actividad profesional del abogado ${ }^{64}$.

A su vez, en relación a las obligaciones de fianza, en su auto de 19 de noviembre de $2015^{65}$, asunto Tarcău, se aparta de lo dispuesto con anterioridad en la sentencia Dietzinger, al sostener que la Directiva 93/13/CEE debe interpretarse en el sentido de que puede aplicarse a un contrato de garantía inmobiliaria o de fianza celebrado entre una persona física y una entidad de crédito para garantizar las obligaciones que una sociedad mercantil asumió contractualmente frente a esa entidad en el marco de un contrato de crédito, cuando dicha persona física no tiene ninguna relación profesional con la citada sociedad.

Por otro lado, en cuanto a la posibilidad de que pueda ser considerado consumidor el fiador, aunque el contrato de garantía o fianza sea accesorio al contrato principal, la respuesta es afirmativa. El TJUE considera que estamos ante un contrato distinto desde el punto de vista de las partes contratantes, ya que se celebra entre personas distintas de las partes en el contrato principal. En este sentido ha sostenido que, «En el caso de una persona física que se constituyó en garante de la ejecución de las obligaciones de una sociedad mercantil, corresponde al juez nacional determinar si dicha persona actuó en el marco de su actividad profesional o por razón de los vínculos funcionales que mantiene con dicha sociedad, como la gerencia de la misma o una participación significativa en su capital social, o bien si actuó con fines de carácter privado»66. En idéntico sentido se pronuncia en el auto de 14 de septiembre de $2016^{67}$,

\footnotetext{
${ }^{63}$ STJUE de 3 de septiembre de 2015, asunto C-110/14, «Horațiu Ovidiu Costea c. SC Volksbank România SA».

${ }^{64}$ El Tribunal fija como doctrina que un abogado o empresario será consumidor siempre y cuando acumulativamente se den dos circunstancias: sea persona física y actúe fuera de su ámbito profesional. Este pronunciamiento es acorde con la STJCE de 22 de noviembre de 2001, en la que establece que en virtud del tenor literal del art. 2.b de la Directiva 93/13/CEE, solamente una persona física puede ostentar la condición de consumidor. Vid. STJCE de 22 de noviembre de 2001, asuntos acumulados C-541/99 y C-542/99, «Cape Snc c. Idealservice Srl y Idealservice MN RE Sas C. OMAI Srl» (apdo. 16). Como será posteriormente analizado, la circunscripción del concepto de consumidor a las personas físicas es una de las principales diferencias entre la definición de consumidor del Derecho de la Unión Europea y la del TRLGDCU, por cuanto este último lo hace extensivo, bajo ciertas condiciones, a las personas jurídicas y a los entes sin personalidad jurídica.

${ }^{65}$ ATJUE de 19 de noviembre de 2015, asunto C-74/15 «Dumitru Tarcău e Ileana Tarcău c. Banca Comercială Intesa Sanpaolo România SA y otros», (en adelante, auto Tarcău).

${ }^{66}$ Apdo. 29 auto Tarcău.

67 ATJUE de 14 de septiembre de 2016, asunto C-534/15, «Pavel Dumitraș y Mioara Dumitraș C. BRD Groupe Société Générale - sucursala Satu Mare».
} 
asunto Pavel Dumitras, en el que concluye que la Directiva 93/13/CEE se aplica a un contrato de garantía inmobiliaria celebrado entre personas físicas y una entidad de crédito para garantizar las obligaciones que una sociedad mercantil ha asumido contractualmente frente a la referida entidad en virtud de un contrato de crédito, cuando esas personas físicas actúen con un propósito ajeno a su actividad profesional y carezcan de vínculos funcionales con la citada sociedad, lo que corresponde determinar al tribunal remitente ${ }^{68}$.

Por último, la jurisprudencia comunitaria ha considerado que la intención lucrativa no debe ser un criterio de exclusión para la aplicación de la noción de consumidor. Así lo ha puesto de manifiesto, entre otras, en la STJCE de 10 abril $2008^{69}$, asunto Hamilton, que resolvió sobre los requisitos del derecho de desistimiento en un caso de contrato de crédito para financiar la adquisición de participaciones en un fondo de inversión inmobiliaria; o en la STJCE 25 octubre 200570, asunto Schulter, sobre un contrato de inversión.

\subsection{El consumidor medio y vulnerable}

Las normas en materia de protección de los consumidores giran en torno a un prototipo de sujeto, o lo que es lo mismo, a una concepción determinada del consumidor. Sería aquél que reúne una serie de condiciones -comunes a la generalidad de los consumidores- que le sitúan en una posición de desventaja frente al empresario con el que contrata ${ }^{71}$. Esta figura podría equipararse a la del buen padre de familia o a la del ordenado comerciante, empleadas en el Derecho Civil y Mercantil respectivamente, con el objeto de delimitar la diligencia exigida en determinadas actuaciones ${ }^{72}$.

Vid. LYCZKOWSKA, K., «¿Es consumidor una persona física que otorga una garantía a favor de una sociedad mercantil?», en Revista CESCO de Derecho de Consumo, 5 de noviembre de 2016.

68 Como señala el Abogado General en los puntos 28 a 33 de sus conclusiones, el concepto de «consumidor», en el sentido del art. 2, letra b), de la Directiva 93/13, tiene un carácter objetivo y es independiente de los conocimientos concretos que pueda tener la persona de que se trata, o de la información de que dicha persona realmente disponga. De este modo, el juez nacional debe tener en cuenta todas las circunstancias del caso susceptibles de demostrar con qué finalidad se adquiere el bien o el servicio objeto del contrato considerado $y$, en particular, la naturaleza de dicho bien o de dicho servicio. Por ello, un abogado que celebra, con una persona física o jurídica que actúa en el marco de su actividad profesional, un contrato que, por no estar referido, en particular, a la actividad de su bufete, no está vinculado al ejercicio de la abogacía, se encuentra, con respecto a dicha persona, en la situación de inferioridad.

69 STJCE de 10 abril de 2008, asunto C-412/06, «Annelore Hamilton C. Volksbank Filder eG».

70 STJCE de 25 de octubre de 2005, asunto C-350/03, «Elisabeth Schulte y Wolfgang Schulte c. Deutsche Bausparkasse Badenia AG».

${ }^{71}$ CÁmARA LAPUENTE, S. (Dir.), Comentarios a las..., cit., p. 549.

72 ZURUTUZA ARIGITA, I., «Perspectiva comunitaria, estatal y autonómica del concepto de consumidor», BIB 2013/1417, Revista Doctrinal Aranzadi Civil-Mercantil, núm. 6/2013 (Estudio), Aranzadi SA, Pamplona, 2013, p. 24. 
Este sujeto de referencia sería aquél que, por guardar las cautelas mínimas exigibles, estaría en disposición de exigir la especial protección que la norma aplicable contemple a su favor. A contrario sensu, la prueba de la ausencia de diligencia propia del consumidor medio en su actuación sería causa justificativa de su exclusión del ámbito de aplicación de la norma $^{73}$. A estos efectos puede decirse que la normativa en materia de protección de los consumidores está destinada al consumidor que reúna los requisitos mínimos exigibles a los que acabamos de hacer mención.

La noción de «consumidor medio», sin embargo, no sirve únicamente a la finalidad arriba descrita, esto es, a la identificación de los sujetos concretos que deban quedar amparados por la norma aplicable al caso. En ámbitos específicos como lo son, fundamentalmente, el de la publicidad contenida en el etiquetado de los productos, los referidos al carácter distintivo y/o descriptivo de las marcas, etc., esta noción opera también como criterio determinante de la consideración de una actuación como ilícita o no, en atención precisamente al impacto que su mensaje cause en el «consumidor medio». Este último uso del término consumidor no debe confundirse con el concepto genérico empleado por Directivas y otros textos legales, precisamente porque responden a finalidades diversas ${ }^{74}$. Las notas que definen al consumidor medio en el segundo sentido señalado se han ido perfilando en la jurisprudencia del Tribunal de Luxemburgo $^{75}$.

La primera resolución en la que se introduce el concepto de «consumidor razonablemente informado» es la sentencia de 6 de julio de $1995^{76}$, asunto Mars. En su fundamentación, el TJCE establece que «no

73 Señala a este respecto B. HeRnÁndez BATALleR, «La protección de los consumidores en la Unión Europea y la Directiva 85/577/CEE: Situación actual y perspectivas de futuro» en A. AzPARRen luCAS, (Dir.), Hacia un código del consumidor, Manuales de formación continua, CGPJ, Escuela Judicial, 2006, p. 436, que «Esta noción específica de consumidor configura una delimitación al concepto de consumidor, en la cual se exige como presupuesto para la aplicación de la norma de protección que se trate de una persona medianamente informada y atenta en consideración a su entorno social, lo cual no es fácil de determinar y dependerá de las circunstancias del caso específico y del buen criterio del juez o autoridad competente. Lo que sí podemos asumir es que se busca que el consumidor sea responsable en su actitud de consumo, de tal forma que, si se evidencia torpeza o desinformación en su conducta por lógicas razones, pierde el derecho a ser protegido».

${ }^{74}$ S. CÁmARA LAPUENTE, (Dir.), Comentarios a las..., cit., p.549.

${ }^{75}$ A propósito de esta jurisprudencia vid. un análisis completo en L. GonZÁLEZ VAQUÉ, «La noción de consumidor medio según la jurisprudencia del Tribunal de Justicia de las Comunidades europeas», en Revista de Derecho Comunitario Europeo, Año 8, núm. 17, enero-abril 2004 y L. GonZÁLEZ VAQUÉ, «Las nociones de consumidor medio y miembro de un grupo particular de consumidores en el reglamento 1924/2006», en Gaceta Jurídica de la Unión Europea y de la Competencia, núm. 247, 9-19, 2007.

76 STCE de 6 de julio de 1995, asunto C-470/93, «Verein gegen Unwesen in Handel und Gewerbe Köln e.V. c. Mars GmbH» (en adelante, sentencia Mars).

Declaraba el Alto Tribunal Europeo en el presente caso que «El artículo 28 [CE] debe interpretarse en el sentido de que se opone a que una medida nacional prohíba la importación y la comercialización de un producto comercializado legalmente en otro Estado miembro, cuya cantidad haya sido aumentada con motivo de una campaña publicitaria de corta duración y cuyo envoltorio contenga la mención "+10\%", 
existe necesariamente un nexo entre el tamaño de las menciones publicitarias relativas a un aumento de la cantidad del producto y la importancia de dicho aumento ${ }^{77}$, siendo necesario a estos efectos, evaluar el impacto que cause esta publicidad en el consumidor razonablemente informado ${ }^{78}$.

A su vez, en la STJCE de 16 de julio $1998^{79}$, asunto Gut Springenheide, al valorar si una mención en el etiquetado -cuyo objetivo era incentivar las ventas de huevos- podía inducir a error al comprador, incorpora un nuevo eje de referencia en orden a determinar la influencia del producto en el consumidor, a saber, el de la «expectativa» que pueda presumirse en un consumidor medio, normalmente informado $y$ razonablemente atento y perspicaz.

Desde entonces, el concepto de «consumidor medianamente informado» ha sido reiteradamente utilizado como parámetro de referencia en sus resoluciones. Así, en la STJCE de 4 de abril de $2000^{80}$, asunto Darbo, al analizar si la mención «puramente natural» inscrita en la etiqueta de una mermelada podía inducir al consumidor a engaño, contesta en sentido negativo, al considerar que el consumidor medio, normalmente informado y razonablemente atento y perspicaz, debe cerciorarse del carácter íntegramente natural del producto acudiendo al listado de ingredientes ${ }^{81}$. Por el contrario, en su STJUE de 4 de junio de $2015^{82}$, asunto Teekanne, en un caso semejante al anteriormente analizado, en el que debía decidir si la representación figurativa de un

a) En razón de que dicha presentación pueda inducir al consumidor a pensar que el precio de la mercancía ofrecida es idéntica a aquel al que hasta entonces se vendía en su antigua presentación. $Y$

b) En razón de que la nueva presentación produce en el consumidor la impresión de que se ha aumentado considerablemente el volumen o el peso del producto».

77 Apdo. 24 sentencia Mars.

78 En resoluciones anteriores, como las que siguen: SJCE de 7 de marzo de 1990, asunto C-362/88, «GB-INNO-BM C. Confédération du commerce»; de 13 de diciembre de 1990, asunto C-238/89, «Pall Corp. C. P. J. Dahlhausen \& Co»; de 18 de mayo de 1993, Casunto 126/91, «Schutzverband gegen Unwesen in der Wirtschaft e.V. C. Yves Rocher $\mathrm{GmbH}$ »; de 2 de febrero de 1994, asunto C-315/92, «Verband Sozialer Wettbewerb eV c. Clinique Laboratoires SNC y Estée Lauder Cosmetics GmbH» (en adelante, sentencia Verband); y de 29 de junio de 1995, asunto C-456/93, «Zentrale zur Bekämpfung unlauteren Wettbewerbs e.V. c. Privatkellerei Franz Wilhelm Langguth Erben GmbH \& Co. $K G . »$; el TJCE había esgrimido un razonamiento semejante, sin embargo, la alusión al consumidor razonablemente se detecta en la sentencia «Mars» por primera vez.

Vid. L. GonzÁlez VAQUÉ, «La noción de consumidor medio según la jurisprudencia del Tribunal de Justicia de las Comunidades europeas», en Revista de Derecho Comunitario Europeo, Año 8, núm. 17, enero-abril 2004, pp. 57 y ss.

79 STJCE de 16 de julio 1998, asunto C-210/96, «Gut Springenheide GmbH y Rudolf Tusky contra Oberkreisdirektor des Kreises Steinfurt - Amt für Lebensmittelüberwachung».

${ }^{80}$ STJCE de 4 de abril de 2000, asunto C-465/98, «Verein gegen Unwesen in Handel und Gewerbe Köln eV c. Adolf Darbo AG», (en adelante, sentencia Darbo).

${ }^{81}$ Apdo. 22 sentencia Darbo.

82 STJUE de 4 de junio de 2015, asunto C-195/14, «Bundesverband der Verbraucherzentralen und Verbraucherverbände - Verbraucherzentrale Bundesverband e.V. c. Teekanne GmbH \& Co. KG», (en adelante, sentencia Teekanne). 
ingrediente en el etiquetado de un producto podía inducir a engaño al consumidor, responde en sentido afirmativo, al considerar que la presencia de esta imagen -en aquella ocasión era una fresa- en el envase del producto, genera la impresión en un consumidor medio, normalmente informado y razonablemente atento y perspicaz, de que tal ingrediente está presente en ese producto alimenticio, y ello, aun cuando de la lista de ingredientes que figura en el envase se desprenda lo contrario ${ }^{83}$.

A su vez, el TJUE en algunos de sus pronunciamientos ha puesto de manifiesto que el grado de diligencia exigida al consumidor medio también se modula en función del tipo de producto. Así lo destaca, entre otras, en la STJUE de 15 de noviembre de $2007^{84}$, asunto Comisión c. Alemania, en la que a propósito del modo de presentación de un medicamento, señala que «ha de tenerse en cuenta la actitud de un consumidor medianamente informado a quien la forma que adopta un producto pudiera inspirarle una especial confianza, semejante a la que inspiran habitualmente los medicamentos habida cuenta de las garantías que ofrecen su fabricación y comercialización» ${ }^{85}$. En igual sentido se pronuncia en la STJUE de 3 de septiembre de $2009^{86}$, asunto Koipe c. OAMI, en la que en relación a la confusión entre marcas de aceite de oliva, declara que el grado de atención exigida al consumidor normalmente informado y razonablemente atento y perspicaz, «puede variar en función de la categoría de productos o servicios de que se trate» ${ }^{87}$.

Este concepto jurisprudencial fue trasladado al Derecho Derivado por medio de la Directiva 2005/29, relativa a las prácticas comerciales desleales de las empresas en relación con sus consumidores, aunque en su articulado definió al consumidor en su sentido tradicional y no incluyó el concepto de consumidor medio ${ }^{88}$. De acuerdo con artículo 5.1 b) de la Directiva, una práctica comercial sólo será desleal si además de ser contraria a los requisitos de la diligencia profesional, «distorsiona o puede distorsionar de manera sustancial, con respecto al producto del que se trate, el comportamiento económico del consumidor medio al que afecta o

\footnotetext{
${ }^{83}$ Apdos. 40 a 44 sentencia Teekanne.

${ }^{84}$ STJUE de 15 de noviembre de 2007, asunto C-319/05, «Comisión de las Comunidades Europeas contra República Federal de Alemania», (en adelante, sentencia Comisión c. Alemania).

${ }^{85}$ Apdo. 47 sentencia Comisión c. Alemania.

${ }^{86}$ STJUE de 3 de septiembre de 2009, asunto C-498/07, «Aceites del Sur-Coosur SA C. Koipe Corporación SL y Oficina de Armonización del Mercado Interior (marcas, dibujos y modelos) (OAMI)», (en adelante, sentencia Koipe c. OAMI).

87 Apdo. 47 sentencia Koipe c. OAMI.

88 Con carácter previo, la definición de consumidor medio había sido incluida en la «Propuesta de Reglamento del Parlamento Europeo y del Consejo sobre las alegaciones nutricionales y de propiedades saludables en los alimentos» (Documento COM (2003) 424 final de 16 de julio de 2003), presentada por la Comisión en julio de 2003. La definición que figuraba en dicha propuesta era la que sigue: «se entenderá por consumidor medio el consumidor que esté razonablemente bien informado y sea razonablemente observador y prudente».
} 
al que se dirige la práctica, o del miembro medio del grupo, si se trata de una práctica comercial dirigida a un grupo concreto de consumidores» ${ }^{89}$.

Por su parte, el Reglamento 1924/06 de la Unión Europea sobre las declaraciones nutricionales y de propiedades saludables en los alimentos, manifiesta de manera casi calcada a la Directiva 2005/29, que con el objeto de permitir la aplicación efectiva de las disposiciones de protección que contiene, toma como referencia al consumidor medio, que está normalmente informado y es razonablemente atento y perspicaz, teniendo en cuenta factores sociales, culturales y lingüísticos, según la interpretación que de este concepto ha hecho el Tribunal de Justicia.

En otro orden de cosas, la definición del TJUE del consumidor medio típico debe modularse para garantizar que cuando el objetivo de una determinada actividad empresarial sea un grupo específico de consumidores, se tomen en cuenta las características del miembro medio de ese grupo al evaluar el impacto de la práctica en cuestión. El Reglamento 1924/2006 en su considerando 16 hacía mención específica a la noción de «grupo particular de consumidores», refiriéndose al evento en que una declaración se dirija a un grupo determinado de personas, caso en el cual debe tenerse en cuenta el impacto que esta información tenga en el «miembro medio» de ese grupo.

A este respecto, la Directiva 2005/29/CE del Parlamento Europeo y del Consejo, alerta por vez primera de la importancia de tomar en consideración la mayor vulnerabilidad de ciertos consumidores cuya voluntad no está totalmente formada, en orden a configurar el concepto de consumidor medio, ya que se incurre el riesgo de que las prácticas comerciales puedan ejercer sobre ellos una «influencia indebida» ${ }^{90}$.

Frente al concepto de «consumidor medio»-que ha sido tildado de regresivo por parte de la doctrina ${ }^{91}$ - cobra especial importancia la Estrategia de refuerzo de los derechos de los consumidores vulnerables,

\footnotetext{
${ }^{89} \mathrm{Ni}$ que decir tiene que el nuevo concepto de consumidor medio, entendido como sujeto normalmente informado y razonablemente atento y perspicaz, supone una importante regresión en el ámbito subjetivo de aplicación de las normas europeas de protección del consumidor. En este sentido, un efecto extensivo a otras áreas sectoriales del Derecho del Consumo comunitario arruinaría buena parte de los logros conseguidos hasta la fecha. Por este motivo, atendiendo al principio pro consumatore, postulamos una interpretación restringida de la aplicación del concepto de consumidor medio, de modo que quede residenciado en el ámbito de las prácticas comerciales desleales, ya sean engañosas o agresivas.

${ }^{90} \mathrm{~A}$ estos efectos establece expresamente en su considerando 19 que «Cuando determinadas características como la edad, una dolencia física o un trastorno mental o la credulidad hagan que los consumidores sean especialmente sensibles a una práctica comercial o al producto correspondiente $y$, con toda probabilidad, únicamente el comportamiento económico de tales consumidores sea susceptible de distorsión merced a la práctica en cuestión en un sentido que el comerciante pueda prever razonablemente, debe garantizarse que estén adecuadamente protegidos, para lo cual es necesario que la práctica se evalúe desde la perspectiva de un miembro medio de ese grupo» ${ }^{90}$. En idéntico sentido se pronuncia en su art. 3.

91 J. CAYÓN DE LAS CUEVAS, «Configuración normativa y técnicas de tutela del consumidor en el Derecho de la unión Europea» en J. L. Tomillo URBINA, (Dir.), La protección jurídica de los consumidores en el espacio euroamericano, Comares, Granada, 2014, pp. 58 a 59.
} 
aprobada por Resolución del Parlamento Europeo, de 22 de mayo de $2012^{92}$. Y, ello, por cuanto señala que la diversidad de las situaciones de vulnerabilidad, ya sea cuando el consumidor queda sujeto a un régimen de protección legal como cuando se encuentra en una situación de vulnerabilidad sectorial o temporal específica, dificulta un planteamiento unitario y la adopción de un instrumento legislativo global, lo cual ha propiciado que tanto la legislación como las políticas existentes aborden el problema de la vulnerabilidad caso por caso. Subraya, por tanto, que la legislación europea debe abordar el problema de la vulnerabilidad desde una perspectiva transversal, teniendo en cuenta sus distintas necesidades, capacidades y circunstancias.

\section{LA NOCIÓN DE CONSUMIDOR EN LA NORMATIVA ESPAÑOLA 3.1. En LA LGDCU y en el TRLGDCU}

La noción de consumidor por la que se decanta el artículo 1.2 de la derogada LGDCU, parte de la idea del destino final del bien o servicio adquirido en el mercado. Lo hace desdoblando esta idea, en clave positiva y negativa, en los apartados segundo y tercero respectivamente. Así, el apartado segundo incide en que podrán ser consumidores quienes adquieran, utilicen o disfruten estos bienes o servicios ${ }^{93}$, y en el tercero que quedarán excluidos de la consideración de tales, quienes integren en procesos de producción, transformación, comercialización o prestación a terceros, los bienes y servicios adquiridos ${ }^{94}$.

La definición reproducida planteaba serias dudas en su aplicación práctica, no sólo por la evidente complejidad de los términos en que venía expresada, sino también porque su literalidad acogía dentro del concepto

92 Vid. la Resolución del Parlamento Europeo, de 22 de mayo de 2012, sobre una estrategia de refuerzo de los derechos de los consumidores vulnerables (2011/2272(INI)).

93 El art. 1.2 de la derogada LGDCU, en la definición de consumidor que ofrece, incluye tanto al consumidor legal (el que adquiera) como el material (el que utilice o disfrute). Luego veremos que en un afán sintetizador, el Texto Refundido, en lugar de referirse a las personas físicas que adquieran, utilicen o disfruten, lo hará a las personas físicas o jurídicas que actúen en un ámbito ajeno a una actividad empresarial. A este respecto, la doctrina ha convenido en considerar que el término actuar debe ser interpretado en su sentido más amplio, comprensivo, por consiguiente, de unos y otros. Así lo ha interpretado, entre otros, S. CÁmARA LAPUENTE, (Dir.), Comentarios a las..., cit., pp. 112 a 113.

La distinción entre el consumidor material y jurídico es igualmente asumida por el Diccionario de la Real Academia de la Lengua en su $22^{\mathrm{a}}$ ed., por cuanto atribuye a la voz consumidor la doble significación que a continuación se indica: aquel «que consume» y «persona que compra bienes de consumo».

${ }^{94}$ Literalmente rezaba el derogado precepto del modo que sigue: «A los efectos de esta Ley, son consumidores o usuarios las personas físicas o jurídicas que adquieren, utilizan o disfrutan como destinatarios finales, bienes muebles o inmuebles, productos, servicios, actividades o funciones, cualquiera que sea la naturaleza pública o privada, individual o colectiva de quienes los producen, facilitan, suministran o expiden.

No tendrán la consideración de consumidores o usuarios quienes sin constituirse en destinatarios finales, adquieran, almacenen, utilicen o consuman bienes o servicios, con el fin de integrarlos en procesos de producción, transformación, comercialización o prestación a terceros» (Arts. 1.2 y 3 LGDCU). 
de consumidor, de manera cuestionable, a ciertos consumidores empresariales. Como contrapartida excluía y, por consiguiente desamparaba, a determinados sujetos que estando inmersos en relaciones de consumo desequilibradas, necesariamente debieran gozar de la consideración de consumidores, entre otros, el consumidor-inversor, el consumidor intermedio o intermediario y el consumidor que vende a un empresario ${ }^{95}$.

Por otro lado, el concepto de consumidor de la LGDCU se distanciaba notablemente del acogido por las Directivas Comunitarias. Y ello, no sólo porque en lugar de asumir la noción negativa, optase por construir su definición en torno a la idea del destino final del bien o servicio, sino fundamentalmente porque extendía el concepto de consumidor a las personas jurídicas ${ }^{96}$. Esta última, sin embargo, es una peculiaridad propia de nuestro ordenamiento que ha sido respetada en las sucesivas definiciones de consumidor que han venido a sustituir a la primigenia.

Así, el TRLGDCU -dejando a salvo la protección de las personas jurídicas como característica propia de nuestro ordenamiento- adapta la definición de consumidor que incorpora a través de su artículo 3 a la línea seguida por el Derecho Derivado de la Unión Europea ${ }^{97}$ : «A efectos de esta norma y sin perjuicio de lo dispuesto expresamente en sus libros tercero y cuarto, son consumidores o usuarios las personas físicas o jurídicas que actúan en un ámbito ajeno a una actividad empresarial o profesional». Ello no obstante, el TRLGDCU conserva vestigios del artículo 1.2 LGDCU a través de su Exposición de Motivos, al disponer que el consumidor es aquél «que interviene en las relaciones de consumo con fines privados, contratando bienes y servicios como destinatario final, sin incorporarlos, ni directa, ni indirectamente, en procesos de producción, comercialización o prestación a terceros» (apdo. III) ${ }^{98}$.

95 Buena parte de los pronunciamientos judiciales en torno al concepto de consumidor bajo la vigencia de la LGDCU, giraban en torno a la interpretación de lo que por «destinatario final» debiera entenderse.

96 De esta extensión no se encuentra ni rastro a lo largo de las diversas Directivas y Reglamentos de la Unión Europea, tampoco en el borrador del llamado «Marco Común de Referencia» (DCFR de 2009) y otros textos de revisión del acervo comunitario (Propuesta de Directiva de los Derechos de los Consumidores de 2008, Acquis Principles de 2007), entre otros.

97 A este respecto es necesario advertir que con carácter previo a la promulgación del TRLGDCU otras normas españolas acogieron el concepto comunitario de consumidor. Es el caso de la Ley $7 / 1995$, de crédito al consumo, que a través de su art. 1.2 disponía que «a los efectos de esta Ley se entenderá por consumidor a la persona física que, en las relaciones contractuales que en ella se regulan, actúa con un propósito ajeno a su actividad empresarial o profesional». En igual sentido, la Ley 22/2007, de 11 de julio, sobre comercialización a distancia de servicios financieros destinados a los consumidores (art. 5 III), por cuanto disponía que «A los efectos de esta Ley, se consideran como consumidores las personas físicas que, en los contratos a distancia, actúan con un propósito ajeno a su actividad empresarial o profesional» (párr. $3^{\circ}$ ).

${ }_{98}$ La presencia de estas previsiones ha motivado que nuestra doctrina se plantee el valor de las precisiones en dicha Exposición contenidas, vid. En tal sentido S. CÁmARA LAPUENTE, (Dir.), Comentarios a las..., cit., pp. 95 y ss. 
Por otro lado, mantiene junto al término consumidor el de «usuario», cuando pudiera haber optado, siguiendo la estela del Derecho de la Unión Europea, por prescindir de este último. A este respecto, como sostiene un sector de la doctrina, el empleo del vocablo consumidor como comprensivo también de los usuarios encuentra su legitimidad en la idea ya consolidada de que el usuario no es sino un consumidor de servicios ${ }^{99}$. La única diferencia entre unos y otros reside en el tipo de relación jurídica a la que vienen referidos, salvada la cual, los dos términos pueden ser acuñados de sinónimos ${ }^{100}$.

Con todo, al margen de la preferencia por una u otra fórmula, nos sumamos al parecer de CámARA LAPUENTE cuando señala que lo verdaderamente importante es el mantenimiento de un criterio estable. Así, compartimos la crítica que vierte este autor en relación al manejo por parte del TRLGDCU de las referidas expresiones, pues si bien inicialmente se decanta por el empleo de la fórmula «consumidores y usuarios», posteriormente hace uso de la expresión «consumidores» en ciertos preceptos que regulan relaciones jurídicas referibles únicamente a los «usuarios de servicios» ${ }^{101}$.

99 Vid. por todos R. Bercovitz Rodríguez CANo, en R. Bercovitz Rodríguez CANo, (Dir.), Comentarios al Texto Refundido de la Ley General para la Defensa de los Consumidores y Usuarios y otras Leyes Complementarias, Aranzadi, Pamplona, 2015, p. 56 y 66 y ss., quien sostiene que el añadir la palabra usuario no implica que se extienda el ámbito de aplicación a sujetos que no son consumidores, ya que los usuarios quedan comprendidos en los consumidores.

Ello no obstante, también encontramos partidarios de la distinción entre los consumidores y los usuarios. Es el caso de A. BERCOVITZ RODRÍGUEZ CANO, para quien hablar también de usuarios «es acertado desde el momento mismo en que se admite hoy con unanimidad que también han de ser protegidos como consumidores quienes adquieren o hacen uso de servicios proporcionados por los Empresarios o por las Administraciones públicas», en R. Bercovitz Rodríguez-CANo; J. SALAS Hernández, (Coords.), Comentarios a la Ley General para la Defensa de los Consumidores y Usuarios", Thomson Civitas, Madrid, 1992, p. 26.

Por su parte, Y. De LUCCHI LóPEZ-TAPIA, La tutela jurisdiccional..., cit., p. 49, n. p. 134, apunta que la distinción entre unos y otros orientada únicamente a la tipología de objetos que se adquieren, unos para ser consumidos y otros para ser utilizados, quizás sea baladí, por cuanto el término consumidor podría ser empleado en su sentido más amplio. Ello no obstante, llama la atención sobre la circunstancia de que otros ordenamientos jurídicos sería el caso, como apunta, del italiano, han llevado a cabo el proceso inverso, esto es, han pasado a contemplar recientemente a los usuarios (separadamente de los consumidores) como sujetos protegibles en este contexto, precisamente por entender que éstos no podían entenderse incluido en la noción de consumidor a la sazón vigente.

100 En este sentido se ha pronunciado, entre otros, S. CÁmARA LAPUENTE (Dir.), Comentarios a las Normas de Protección de los Consumidores. Texto Refundido (RDL 1/2007) y otras leyes y reglamentos vigentes en España y en la Unión Europea, Colex, 2011 , p. 129; J. M. LóPEZ JIMÉNEZ, «Las acciones colectivas como medio de protección de los derechos e intereses de los consumidores», en Diario La Ley, núm. 6852, Sección Doctrina, 2 Ene. 2008, Año XXIX, Ref. D-1, La Ley, La Ley 6866/2007, p. 2.

101 Arts. 102 y 148.1 ; cfr. art. 85.2, sobre servicios financieros con empleo solitario del término «consumidor» o también en el art. 49.1 j sobre «contratos de prestación de servicios». 
La promulgación en el año 2007 del TRLGDCU constituyó una oportunidad perdida de introducir en el ordenamiento interno el concepto exclusivo de «consumidor» ${ }^{102}$ y tampoco ahora, por medio de la Ley $3 / 2014$, de 27 de marzo, por la que se modifica el Texto Refundido de la Ley General de Consumidores y Usuarios y otras leyes complementarias (en adelante, Ley $3 / 2014)^{103}$, se ha incidido en esta cuestión.

\subsection{En el TRLGDCU tras la LEY $3 / 2014$}

Tras la aprobación de la Ley $3 / 2014$ se ha procedido a la modificación de ciertos aspectos contenidos en el TRLGDCU, entre los que se encuentra el propio concepto de consumidor que acaba de ser reproducido, siendo la nueva redacción dada al mismo la que sigue: «A efectos de esta norma y sin perjuicio de lo dispuesto expresamente en sus libros tercero y cuarto, son consumidores y usuarios las personas físicas que actúen con un propósito ajeno a su actividad comercial, empresarial, oficio o profesión.

Son también consumidores a efectos de esta norma las personas jurídicas y las entidades sin personalidad jurídica, que actúan sin ánimo de lucro en un ámbito ajeno a una actividad comercial o empresarial» ${ }^{104}$.

102 A propósito de esta cuestión sostiene S. CAVANillas MúGICA, «El Real Decreto Legislativo 1/2007, por el que se aprueba el texto refundido de la Ley General para la Defensa de los Consumidores y Usuarios y otras leyes complementarias», en Aranzadi Civil, 1/2008, versión electrónica, Base de datos Westlaw-Aranzadi, referencia BIB $2008 / 24$, p. 5, que «el texto jurídico español no padecería mucho [...] por aceptar que es también consumidor el prestatario de un servicio, el arrendatario de un vehículo de alquiler o quien usa un producto o servicio que no ha contratado personalmente». En igual sentido se pronuncia FeRnández CARBALlo-CALERO, P., «El concepto de consumidor en el Texto refundido de la Ley General para la Defensa de los Consumidores y Usuarios», en Gómez Segade, J. A., García Vidal, A. (Eds.), El Derecho Mercantil en el umbral del s. XXI. Libro homenaje al Prof. Dr.: Carlos Fernández Nóvoa en su octogésimo cumpleaños, Marcial Pons, Barcelona, 2010; BerCovitz Rodríguez CANo, R. (Coord.), Comentario del Texto Refundido de la Ley General para la Defensa de los Consumidores y Usuarios y otras leyes complementarias (Real Decreto Legislativo 1/2007), Aranzadi, Cizur Menor (Navarra), 2009, pp. 96 a 98; y CÁmARA LAPUENTE, S. (Dir.), Comentarios a las..., cit., p. 129; Bercovitz Rodríguez Cano, R. (Coord.), Comentario del Texto Refundido de la Ley General para la Defensa de los Consumidores y Usuarios y otras leyes complementarias (Real Decreto Legislativo 1/2007), Aranzadi, Cizur Menor(Navarra),2009, pp. 96 a 98.

${ }^{103}$ Esta Ley tiene por objeto, por un lado, la modificación de la normativa europea en materia de cláusulas abusivas en los contratos celebrados con consumidores y sobre determinados aspectos de la venta y garantías de los bienes de consumo y, por otro, a la derogación de la normativa europea vigente sobre la protección de los consumidores en los contratos celebrados a distancia y los contratos celebrados fuera de los establecimientos mercantiles, estableciendo un nuevo marco legal en esta materia.

${ }^{104}$ Del tenor literal del art. 3 del TRLGDCU se desprende ( $y$ este aspecto se ha mantenido invariable) que su alcance no abarcará a la totalidad de los derechos comprendidos en el texto de la norma, concretamente, a los supuestos referidos a los Libros III y IV.

El Libro III, que incorpora la Ley 22/1994, de 6 de julio, de responsabilidad civil por los daños causados por productos defectuosos, no contempla un concepto específico de consumidor. Ello no obstante, la referencia del art. 128 a «todo perjudicado» permite concluir que la norma protege a toda persona física por los daños personalmente ocasionados por un producto defectuoso. Como pone de relieve GUTIÉRREZ SANTIAGo, esta previsión vendría a erigirse en una excepción a lo dispuesto en el art. 2 del Texto Refundido, en cuya virtud el Texto Refundido «será de aplicación a las relaciones entre 
Como puede observarse, la nueva redacción del artículo 3 del TRLGDCU incluye dos modalidades de consumidor, por un lado, el consumidor persona física -al que viene referido el párr. $1^{0}-y$, por otro, los consumidores persona jurídica y ente sin personalidad -a los que alude en su párr. $2^{{ }^{-}}$.

\subsubsection{El consumidor persona física}

Por lo que concierne al consumidor persona física, al comparar su regulación con la del derogado precepto, comprobamos que las tres modificaciones que introduce no son sustanciales. El artículo 3 del TRLGDCU, previa su modificación, establecía que «son consumidores o usuarios las personas físicas [...] que actúan en un ámbito ajeno a una actividad empresarial o profesional» $\mathrm{y}$, tras la reforma, ha pasado a disponer que «son consumidores y usuarios las personas físicas que actúen con un propósito ajeno a su actividad comercial, empresarial, oficio o profesión».

En primer lugar, observamos que mientras que su redacción originaria establecía que el consumidor debía actuar «en un ámbito ajeno» a una actividad empresarial, la vigente redacción requiere, sin embargo, que el consumidor actúe «con un propósito ajeno» a la misma. A este respecto, tal y como ha sostenido MARÍn LóPEZ ${ }^{105}$, la citada diferencia no acarrea consecuencia alguna, pues si bien la referencia al «propósito» remite a un parámetro subjetivo que haría prevalecer el elemento intencional del sujeto, su combinación con el término «actuar» provoca que lo decisivo sea, no ya el propósito o finalidad perseguida, sino el destino efectivamente dado al bien o servicio recibido ${ }^{106}$.

consumidores o usuarios y empresarios», pues por lo que al régimen de responsabilidad civil por productos defectuosos se refiere, si bien es cierto que el productor (fabricante o importador) y el proveedor del producto han de tener necesariamente la condición de empresarios o profesionales, no resulta imprescindible, por la contra, que el perjudicado protegido por este régimen sea estrictamente consumidor o usuario, en GUTIÉRREZ SANTIAGO, P., «Daños causados por productos defectuoso», en Aranzadi Civil, núm. 32/2008, versión electrónica.

Por su parte, el Libro IV, que introduce la Ley 21/1995, de 6 de julio, sobre viajes combinados, sí define por remisión al consumidor o usuario como «cualquier persona en la que concurra la condición de contratante principal, beneficiario o cesionario». A estos efectos, el art. 151.1 considera contratante principal a la persona física o jurídica que compre o se comprometa a comprar el viaje combinado y cesionario a «la persona física a la cual el contratante principal u otro beneficiario ceda el viaje combinado». Vid. Bercovitz Rodríguez Cano, R. (Coord.), Comentario del Texto..., cit., p. 42, o LASARTE Álvarez, C., Manual sobre protección de consumidores y usuarios, Dykinson, Madrid, 2003, pp. 70 y ss.

105 Cabe señalar que los comentarios de este autor vienen referidos al Proyecto de Ley núm. 71-1, de 25 de octubre de 2013, por el que se modifica el TRLGDCU. Ello no obstante, comoquiera que el tenor del precepto comentado se ha mantenido invariable en la Ley $3 / 2014$, son perfectamente aplicables al caso.

106 M. J. MARÍn LóPEZ, «Comentarios al proyecto de ley de reforma de la LGDCU. El «nuevo» concepto de consumidor y empresario en la inminente reforma del TRLGDCU», en Revista del Centro de Estudios de Consumo, diciembre de 2013, p. 2. 
En segundo lugar, si la actuación de la persona física en la anterior regulación debía ser ajena a una «actividad empresarial o profesional», en la vigente debe serlo a su «actividad comercial, empresarial, oficio o profesión», sin que la mención al oficio o profesión añada nada al sentido de la expresión anteriormente utilizada. Tanto la una como la otra resultan redundantes, de modo que hubiera sido preferible que el precepto aludiese únicamente a la actividad empresarial como comprensiva de las restantes ${ }^{107}$.

Por otro lado, la circunstancia de que la nueva redacción incida en la necesidad de que el consumidor, para ser considerado como tal, deba actuar al margen de «su» actividad comercial, en lugar de en un ámbito ajeno a «una» actividad empresarial, nos lleva a la conclusión de que las únicas actividades que quedan excluidas del ámbito de consumo son las directamente ligadas a la actividad profesional que la persona física desempeñe ${ }^{108}$. Así parecen haberlo interpretado algunas sentencias de Audiencias Provinciales, que han venido reconociendo que, en determinados supuestos, quien actúa en el marco de una actividad empresarial que no constituye el objeto de su profesión, puede ser considerado consumidor. Como ejemplos podemos destacar los siguientes: la personaque adquiere un inmueble para su reventa o para alquilarla ${ }^{109}$ sin dedicarse profesionalmente a esa actividad ${ }^{110}$; el confitero

107 M. J. MARÍn LÓPEZ, «Comentarios al proyecto...», cit., p. 3. Como indica BerCovitz Rodríguez-Cano, en R. Bercovitz Rodríguez-Cano, (Dir.), Comentarios al Texto Refundido de La Ley General para la Defensa de los Consumidores y Usuarios, Cizur Menor, Thomson-Aranzadi, 2015, p. 60., del mismo modo que la redacción anterior era redundante, puesto que la referencia a lo profesional debiera quedar comprendida en la referencia a lo empresarial, la alusión al oficio y a la profesional resulta igualmente repetitiva.

108 MARín LóPez, M. J., «Comentarios al proyecto...», cit., p. 4; CámARA LAPUeNTE, S., «Comentario al art. 3», en CÁmARA LAPUenTE, S. (Dir.), Comentarios a las Normas de Protección de los Consumidores, Madrid, Colex, 2011, pp. 139 y 140; y BERCoviTZ RODRÍGUEZ-CANO, R., «Comentario al art. 3», cit., pp. 95 y 96.

${ }^{109}$ Como ha puesto de manifiesto la SAP de Las Palmas (Sección 4a), 625/2014, de 26 de noviembre, el mero hecho de que una de las finalidades de la adquisición de las viviendas pueda ser la inversión, 0 incluso ponerlas en alquiler, no permite excluir la condición de consumidor o usuario del deudor hipotecario cuando en modo alguno la legislación protectora de consumidores y usuarios excluye a quienes tengan, entre otras, la intención de invertir o ahorrar al adquirir las viviendas (y mucho menos a quienes obtengan préstamos para financiar la adquisición de algún bien), sin que pueda tampoco olvidarse que el arrendamiento de viviendas entre particulares es un negocio jurídico privado, por lo que, si no se acredita actividad calificable de empresarial en el sector inmobiliario, el deudor hipotecario se debe encontrar amparado por la normativa de consumidores y usuarios.

En mismo sentido, la SAP de Pontevedra (Sección $1^{a}$ ), 336/2014, de 14 de octubre, establece que el comprador que adquiere una vivienda para luego arrendarla, cuando no realiza esa actividad de forma habitual y no forma parte de su profesión, tiene el concepto de consumidor.

Por consiguiente, será la habitualidad y profesionalidad en el alquiler de viviendas lo que prive al deudor de la condición de consumidor o usuario; en este sentido, se pronuncia la SAP de Vizcaya (Sección 4a), 477/2014, de 30 de julio, en un caso en que se usó parte del préstamo hipotecario para construir un edificio dedicado a actividad empresarial, 
que toma un préstamo para rehabilitar un edificio, actividad ajena a su actividad profesional ${ }^{111}$; los padres que hipotecan su vivienda para garantizar deudas del negocio de su hijo ${ }^{112}$; o el que toma un préstamo para disfrutar de una vivienda de vacaciones que ocasionalmente arrienda ${ }^{113}$.

Lo determinante a estos efectos es, por un lado, el destino que se le da a aquello que se adquiere. Así lo establece la doctrina del TJUE y lo reproduce igualmente nuestro Tribunal Supremo, entre otras, en su STS 246/2014, de 28 de mayo, en la que partiendo del criterio anteriormente indicado, excluye la aplicación de la normativa protectora de los consumidores a una compraventa de un loft o despacho profesional al constatar que el destino del local adquirido quedaba integrado, plenamente, en el marco de su actividad profesional ${ }^{114}$. En igual sentido se pronuncia en su STS 367/2016, de 3 de junio, en la que niega la condición de consumidora a una persona que había suscrito un contrato de préstamo con garantía de hipoteca con la finalidad de financiar la adquisición de un local para la instalación de una farmacia. Formulada demanda para la eliminación de la cláusula suelo por defecto de transparencia, el Supremo considera que este control se aplica únicamente a los contratos de adhesión suscritos con consumidores, por lo que considera que no cabe en este supuesto ${ }^{115}$.

A su vez, es igualmente relevante a los efectos de determinar la condición de consumidor, la ausencia de ánimo de lucro «empresarial» ${ }^{116}$. A este respecto, siguiendo la línea marcada por el TJUE, el Tribunal

alquiler de habitaciones y ello aunque la finca hipotecada era su vivienda habitual (adquirida con anterioridad por donación).

${ }^{110}$ Vid. la SAP Pontevedra (Sección 1a), 14 octubre 2014 y 9 julio 2015.

${ }^{111}$ Vid. la SAP León (Sección $1^{a}$ ), 20 julio 2015.

${ }^{112}$ Vid. la SAP de Álava (Sección 1a), 10 septiembre 2015.

${ }^{113}$ Vid. la SAP Álava (Sección $1^{\mathrm{a}}$ ), 9 diciembre 2015.

${ }^{114}$ En igual sentido, la SAP de Barcelona (Sección 15a) 179/2015, de 8 de julio, deniega la condición de consumidor al sujeto que contrató un préstamo concedido para la adquisición de un inmueble que se iba a destinar, inicialmente, a arrendarlo y así obtener financiación y posteriormente a establecer en él las oficinas de la sociedad, al considerar que el destino del local adquirido queda integrado, plenamente, en el marco de su actividad profesional de prestación de servicios.

${ }^{115}$ Ante este fallo, el Magistrado Excmo. Sr. Don Francisco Javier Orduña Moreno formula un voto particular. La discrepancia del Magistrado radica en la fundamentación que la sentencia desarrolla para justificar la no extensión del control de transparencia a la contratación bajo condiciones generales ente empresarios; particularmente con relación a los pequeños y medianos empresarios que actúan como menor adherentes en dicha contratación.

${ }_{116}$ Aunque no se especifique expresamente, el consumidor persona física ha de carecer de ánimo de lucro empresarial. En este sentido se pronuncia R. BERCOVITZ RodRíGUEZ CANo, «Artículo 3. Concepto...», cit., p. 60.

Ahora bien, debemos aclarar que no todo ánimo de lucro puede ser considerado ánimo de lucro empresarial, a los efectos de descartar la consideración del adquirente como consumidor. Por ello, en determinadas ocasiones, la persona física que actúa movida por cierto ánimo de lucro obtiene la consideración de consumidora. Vid. a este respecto el comentario de MARÍN LÓPEZ, M. J., «Es consumidor el que compra un inmueble para arrendarlo, aunque tenga ánimo de lucro», en Revista CESCO, 18 de febrero de 2015. 
Supremo en su sentencia 16/2017, de 16 de enero, sostiene que: «el ánimo de lucro del consumidor persona física debe referirse a la operación concreta en que tenga lugar, puesto que si el consumidor puede actuar con afán de enriquecerse, el límite estará en aquellos supuestos en que realice estas actividades con regularidad (comprar para inmediatamente revender sucesivamente inmuebles, acciones, etc.), ya que de realizar varias de esas operaciones asiduamente en un período corto de tiempo, podría considerarse que, con tales actos, realiza una actividad empresarial o profesional, dado que la habitualidad es una de las características de la cualidad legal de empresario, conforme establece el art. $1.1^{\circ}$ CCom» (F. J. $\left.4^{\circ}\right)$.

A la vista de que el ánimo de lucro no excluye por sí sólo la consideración de consumidor, cabe sostener que el inversor no profesional puede obtener el amparo de la normativa tuitiva de los consumidores. De hecho, los tribunales han venido considerando sistemáticamente que los inversores no profesionales -contratantes de preferentes, swaps, clips, entre otros productos financieros complejos-, en determinados casos, precisamente por su vulnerabilidad frente a la otra parte contratante, deben ser equiparados a los consumidores ${ }^{117}$. A este respecto, como señala FERNÁNDEZ DE ARAOZ, «se ha evolucionado hacia un "modelo de consumerización de los inversores"», cuyo propósito pasa por intensificar la tutela a un colectivo al que se considera poco capacitado para hacerlo por sí mismo ${ }^{118}$. Y es que lo que realmente convierte la actividad del inversionista en actividad empresarial o comercial es la habitualidad y la afección de bienes de manera prolongada y organizada, por lo que habrá que valorar en cada caso si el sujeto actúa como profesional o como consumidor.

Por su parte, en el Derecho español no existe una respuesta normativa en torno a los supuestos de destino mixto - parcialmente privado parcialmente profesional-; pero sí una respuesta judicial, plasmada, entre otras, en la STS 224/2017, de 5 de abril, en la que el Tribunal Supremo, siguiendo la estela marcada por la sentencia Gruber, dispone que cuando no quede acreditado que un contrato se ha realizado exclusivamente con un propósito profesional o privado «el contratante en cuestión deberá ser considerado como consumidor si el objeto profesional no predomina en el contexto general del contrato, en atención a la globalidad de las circunstancias y a la apreciación de la prueba» (F. J. 40).

\subsubsection{Los consumidores persona jurídica y ente sin personalidad}

Como tuvimos ocasión de avanzar en líneas anteriores, una de las características que presenta el Derecho español en lo que a la definición

\footnotetext{
117 Vid. A. Agüero Ortiz, «El consumidor como inversor de alto riesgo: la impugnación por vicios del consentimiento de los contratos de adquisición de participaciones preferentes y swaps, una opción sólo al alcance de algunos», en Revista CESCO de Derecho del Consumo, núm. 8, 2013.

118 A. FERnÁNDEZ De ARAOZ GómEZ, «Repensar la protección del inversor: bases para un nuevo régimen de la contratación mobiliaria», en Diario La Ley, No 8549, Sección Doctrina, 28 de Mayo de 2015, Ref. D-212, Editorial LA LEY,
} 
de consumidor concierne, es la consideración como consumidores a las personas jurídicas ${ }^{119}$, de modo que el legislador de la Ley 3/2014 únicamente se ha limitado a conservar esta peculiaridad ${ }^{120}$.

Mayor innovación ha supuesto, sin embargo, la extensión del concepto de consumidor a los entes sin personalidad jurídica ${ }^{121}$, con lo que se respalda normativamente una tendencia que ya había sido asumida en la jurisprudencia, en la que venía admitiéndose la consideración de consumidores, entre otros, a las comunidades de propietarios ${ }^{122}$.

Ello no obstante, la norma ha incorporado una serie de elementos condicionantes que deberán concurrir tanto en las personas jurídicas como en los entes sin personalidad que pretendan beneficiarse de la consideración de consumidores. Éstos son los que siguen:

a) Deberán actuar sin ánimo de lucro. A este respecto, y ante la ausencia de indicación alguna acerca de lo que por «ánimo de lucro» a afectos de esta norma deba entenderse, MARÍn LóPEZ ha sostenido que éste habrá de identificarse -siguiendo la única definición que del mismo ofrece nuestro Código Civil respecto de las sociedades- no tanto con el propósito de obtener un beneficio, sino con el de repartirlo entre los socios. Desde este punto de vista, la falta de ánimo de lucro habría de interpretarse, tal y como señala este autor, como una característica «típica» de algunas personas jurídicas 0 entes sin personalidad (asociaciones, fundaciones, comunidades de propietarios ${ }^{123}$, etc.); a contrario sensu serviría para excluir a aquellas personas jurídicas que por

${ }^{119}$ La Directiva 2011/83/UE del Parlamento Europeo y del Consejo, de 25 de octubre de 2011 sobre derechos de los consumidores, dispone en el apartado $13^{\circ}$ del Preámbulo que «los Estados miembros podrán decidir extender la aplicación de lo dispuesto en la presente Directiva a las personas jurídicas o físicas que no sean «consumidores» en el sentido de la presente Directiva, como organizaciones no gubernamentales, empresas de reciente creación o pequeñas y medianas empresas». En igual sentido, la extensión del concepto de consumidor a las pequeñas y medianas empresas en el derecho bancario de la Unión Europea se encuentra ya reconocido.

120 Ello no obstante, cabe apuntar que el ámbito de aplicación de la Ley 16/2011, de contratos de crédito al consumo, se excluye expresamente la consideración como consumidores de las personas jurídicas (art. 2.1).

${ }^{121} \mathrm{La}$ necesidad de proteger a las entidades sin personalidad jurídica que actúan en el tráfico frecuentemente como consumidores fuera del ámbito de una actividad profesional, ya había sido destacada por la doctrina. Es el caso de S. CÁmARA LAPUENTE, (Dir.), Comentarios a las..., cit., p. 97.

${ }^{122}$ A este último respecto, son numerosas las decisiones judiciales en las que se venía aplicando la LGDCU a los litigios planteados entre una comunidad de propietarios y la empresa encargada del mantenimiento y conservación de los ascensores, en el que se discute la consideración como abusivas de algunas cláusulas incluidas en el contrato. Vid. entre otras, las SSTS 14 septiembre 1996; 3 julio 1998; y 20 julio 1998.

123 Según ha señalado la STS 8 de marzo de 1991, la comunidad de propietarios en régimen de propiedad horizontal se encuentra «entre la mera comunidad de bienes y los entes autónomos», o como afirmó la STS de 14 de mayo de 1992, se trata de «un ente de proyección jurídica propia que, si bien actualmente no puede operar sino a través de su representante en juicio y fuera de él, como es el presidente, tenga una estructura y función propia y relevante en el futuro, que se asemeja a las personas jurídicas del art. 35 CC». 
su propia naturaleza tienen ánimo de lucro (sociedades anónimas, sociedades de responsabilidad limitada, etc.).

b) Deberán actuar en un ámbito ajeno a una actividad comercial o profesional. De conformidad con dicha exigencia, las personas jurídicas mercantiles (sociedades anónimas, sociedades de responsabilidad limitada, etc.) quedarían, en todo caso, excluidas de la consideración de personas consumidoras, toda vez que los bienes o servicios que adquieren son destinados, de modo directo o indirecto, a una actividad comercial ${ }^{124}$.

En cuanto a las personas jurídicas «civiles», esto es, las fundaciones y las asociaciones, habría que evaluar su potencial consideración como consumidoras en función del contexto en que la adquisición del bien o servicio se haya llevado a término, pues ambas podrán realizar actuaciones comerciales excluidas e incluidas en el ámbito de protección de los consumidores ${ }^{125}$. Por ejemplo, las asociaciones, y no incluimos las asociaciones de empresarios o profesionales (que nunca obtienen la consideración de consumidores), actúan al margen de una actividad empresarial cuando los bienes o servicios adquiridos revierten directa o indirectamente en sus socios ${ }^{126}$.

\section{BIBLIOGRAFÍA}

ACEDO PENCO, A., «La noción de consumidor y su tratamiento en el Derecho Comunitario, Estatal y Autonómico. Breve referencia al concepto de consumidor en el Derecho extremeño», en Anuario de la Facultad de Derecho, núm. 18, 2000.

AGÜERO ORTIZ, A., «El consumidor como inversor de alto riesgo: la impugnación por vicios del consentimiento de los contratos de adquisición de participaciones preferentes y swaps, una opción sólo al alcance de algunos», en Revista CESCO de Derecho del Consumo, núm. 8, 2013.

BERCOVITZ, R., SALAS, J. (Coords.), Estudios jurídicos sobre protección de los consumidores, Tecnos, Madrid, 1987.

BERCOVITZ RODRÍGUEZ CANO, R. (Coord.), Comentario del Texto Refundido de la Ley General para la Defensa de los Consumidores y Usuarios y otras leyes complementarias (Real Decreto Legislativo 1/2007), Aranzadi, Cizur Menor (Navarra),2009.

${ }^{124}$ En este sentido sostiene A. CARrasco PererA, Texto Refundido de La Ley General..., cit., p. 18, que las sociedades de capital, aun en el caso de que hubieran sido constituidas con el objeto de realizar una actividad sin ánimo de lucro, no podrán ser consideradas como consumidoras.

${ }^{125}$ A este respecto S. CÁmARA LAPUENTE, Comentarios a las normas de protección de los consumidores, Colex, 2011, pp. 132 a 133, se inclina por excluir tanto a las fundaciones como a las cooperativas del concepto de consumidor, pues en su opinión «revisten esos rasgos de operaciones económicas o participantes en el mercado (organización, permanencia, habitualidad por definición ex artículo 2 Ley 50/2001 y actividad económica ex artículo 24.1 de la misma Ley)».

${ }^{126}$ Así lo considera M. J. MARÍn LÓPEZ, «Comentarios al proyecto...», cit., p. 4 
BOTANA GARCÍA, G. A., «La noción de consumidor», en Botana García, G. A., Ruiz Muñoz, M. (Coords.), Curso sobre protección jurídica de los consumidores, McGraw-Hill, Madrid, 1999.

BOURGOIGNIE, T., Elementos para una teoría del Derecho del consumo, Departamento de Comercio, Consumo y Turismo del Gobierno Vasco, Vitoria, 1994.

CÁMARA LAPUENTE, S., «Comentario al art. 3», en Cámara Lapuente, S. (Dir.), Comentarios a las Normas de Protección de los Consumidores, Madrid, Colex, 2011.

CARRILLO POZO, L. F., «Comentarios al art. 13», en Calvo Caravaca, A. L. (Ed.), Comentario al Convenio de Bruselas relativo a la competencia judicial y a la ejecución de resoluciones judiciales en materia civil y mercantil, Universidad Carlos III, Madrid, 1994.

CASTAÑEDA MUÑOZ, J. E., «Nota breve sobre el concepto de consumidor», en Cuadernos de Estudios Empresariales, vol. 12, 2002.

CAVANILLAS MúGICA, S., «El Real Decreto Legislativo 1/2007, por el que se aprueba el texto refundido de la Ley General para la Defensa de los Consumidores y Usuarios y otras leyes complementarias», en Aranzadi Civil, 1/2008, versión electrónica, Base de datos Westlaw-Aranzadi, referencia BIB 2008/24

CAYÓN DE LAS CUEVAS, J., «Configuración normativa y técnicas de tutela del consumidor en el Derecho de la unión Europea» en Tomillo Urbina, J. L. (Dir.), La protección jurídica de los consumidores en el espacio euroamericano, Comares, Granada, 2014.

CORCHERO, M., GRANDE MURILLO, A., La protección de los consumidores. Especial referencia al Estatuto de los Consumidores de Extremadura, Thomson Aranzadi, Pamplona, 2007.

DE LEÓN ARCE, EN DE LEÓN ARCE, A., GARCÍA GARCÍA, L. M. (Coords.), Derechos de los consumidores y usuarios, vol. 1, Tirant lo Blanch, Valencia, 2007.

ESPINO HERNÁNDEZ, L. D., «Razón de ser y evolución de la protección procesal de los consumidores y usuarios», en González Pillado, E. (Coord.), Resolución de conflictos en materia de consumo: proceso y arbitraje, Tecnos, Madrid, 2010.

EXPÓSITO GÓMEZ, E., «La acción de la Unión Europea en la protección de los consumidores», en Olesti Rayo, A. (Coord.), La Incidencia del Tratado de Lisboa en el ejercicio de las competencias autonómicas, Institut d'Estudis Autonòmics, Seminarios, Barcelona, 2009.

FERNÁNDEZ CARBALLO-CALERO, P., «El concepto de consumidor en el Texto refundido de la Ley General para la Defensa de los Consumidores y Usuarios», en Gómez Segade, J. A., GARCía VidAL, A. (Eds.), El Derecho Mercantil en el umbral del s. XXI. Libro homenaje al Prof. Dr.: Carlos Fernández Nóvoa en su octogésimo cumpleaños, Marcial Pons, Barcelona, 2010.

FERNÁNDEZ DE ARAOZ GÓMEZ, A., «Repensar la protección del inversor: bases para un nuevo régimen de la contratación mobiliaria», en Diario La Ley, No 8549, Sección Doctrina, 28 de Mayo de 2015, Ref. D-212, Editorial LA LEY. 
GUILLÉN CARAMÉS, J., «EI marco jurídico de la política comunitaria de protección de los consumidores», en Revista de Derecho de la Unión Europea, núm. $5,2^{\circ}$ semestre 2003.

GUTIÉRREZ SANZ, SAMANES ARA, C., «Comentario al artículo 7.3 de la Ley Orgánica del Poder Judicial en relación con la protección procesal de los derechos de los consumidores», en La Ley, 1988-3.

LASARTE ÁLVAREZ, C., Manual sobre protección de consumidores y usuarios, Dykinson, Madrid, 2003.

LETE ACHIRICA, J., «La armonización de las legislaciones europeas sobre protección de los consumidores a la luz del derecho comunitario», en Actualidad Civil, Sección Doctrina, 1998, Ref. IX.

MARÍN LÓPEZ, M. J., «Es consumidor el que compra un inmueble para arrendarlo, aunque tenga ánimo de lucro», en Revista CESCO, 18 de febrero de 2015.

PAGADOR LÓPEZ, J., La Directiva Comunitaria sobre cláusulas contractuales abusivas, Madrid, 1998.

PARRA LUCÁN, M. A., «Algunos aspectos de las competencias de las Comunidades Autónomas para la protección del consumidor», en Revista Jurídica de Navarra, núm. 4, 1987.

QUINTANA CARLO, I., «La protección del consumidor en España (Aspecto comparativo con la Comunidad Económica Europea)», en Actualidad Civil, Sección Doctrina, 1987, La Ley 5341/2002.

REICH, N., Mercado y Derecho (trad. de Font), Ariel, Barcelona, 1985.

ROMERO GARCÍA-MORA, G., «En torno al concepto de «consumidor» en el Derecho Comunitario. A propósito de la STJCE Gruber vs. Bay Wa», en Actualidad civil, núm. 22, Sección A Fondo, Quincena del 16 al 31 Dic. 2005, p. 2704, La Ley 5132/2005.

ZURUTUZA ARITIGA, I., «Perspectiva comunitaria, estatal y autonómica del concepto de consumidor, en Revista Doctrinal Aranzadi CivilMercantil, núm. 6/2013, Pamplona, 2013. 